\title{
Diabetes patients with comorbidities had unfavorable outcomes following COVID-19: a retrospective study
}

\section{Weihua Hu, MD}

the First Hospital of Jingzhou, Clinical MedicalCollege, Yangtze University

Shunkui Luo

the Fifth Affiliated Hospital of Sun Yat-sen University

\section{Zhanjin Lu, MD}

the Fifth Affiliated Hospital of Sun Yat-sen University

\section{Chang Li}

Hubei No.3 People's Hospital of Jianghan University

\section{Qijian Chen}

the Fifth Hospital in Wuhan

\section{Yameng Fan}

School of Health Sciences, Wuhan University

\section{Zaishu Chen}

People's Hospital of Jiayu County

\section{Longlong Wu}

People's Hospital of Nanzhang county

\section{Jianfang Ye}

the Fifth Affiliated Hospital of Sun Yat-sen University

\section{Shiyan Chen}

the Fifth Affiliated Hospital of Sun Yat-sen University

Junlu Tong

the Fifth Affiliated Hospital of Sun Yat-sen University

\section{Lingling Wang}

the Fifth Affiliated Hospital of Sun Yat-sen University

\section{Jin Mei}

Wenzhou Medical University

Hongyun Lu ( $\square$ luhongy@mail.sysu.edu.cn )

the Fifth Affiliated Hospital of Sun Yat-sen University https://orcid.org/0000-0001-8794-0887

\section{Research}


Keywords: Diabetes, Coronavirus disease 2019, mortality, risk factors, acarbose

Posted Date: November 4th, 2020

DOI: https://doi.org/10.21203/rs.3.rs-57456/v2

License: (c) (i) This work is licensed under a Creative Commons Attribution 4.0 International License. Read Full License 


\section{Abstract}

\section{Background}

Previous studies have shown that diabetes mellitus is a common comorbidity of Coronavirus Disease 2019 (COVID-19), but the effects of diabetes or antidiabetic medication on the mortality of COVID-19 have not been well described. To investigate the outcome of different statuses (with or without comorbidity) and antidiabetic medication use before admission of patients with diabetes after severe acute respiratory syndrome coronavirus 2 (SARS-CoV-2) infection, we collected clinical data of patients with COVID-19 and compared those with diabetes versus nondiabetics.

\section{Methods}

In this multicenter and retrospective study, we enrolled 1,422 consecutive hospitalized patients from January 21 to March 25, 2020, at six hospitals in Hubei Province, China. The primary endpoint was inhospital mortality.

\section{Results}

Patients with diabetes were 10 years older than nondiabetic patients $(p<0.001)$ and had a higher prevalence of comorbidities such as hypertension ( $p<0.001)$, coronary heart disease (CHD) $(p<0.001)$, cerebrovascular disease (CVD) $(p<0.001)$, and chronic kidney disease (CKD) $(p=0.007)$. Mortality $(p=0.003)$ was more prevalent among the diabetes group. Further analysis revealed that patients with diabetes who took acarbose had a lower mortality rate $(p<0.01)$. Multivariable Cox regression showed that male sex (hazard ratio [HR] 2.59 [1.68-3.99]), hypertension (HR 1.75 [1.18-2.60]), CKD (HR 4.55 [2.52-8.20]), CVD (HR 2.35 [1.27-4.33]), and age were risk factors for the COVID-19 mortality. Higher HRs were noted in those aged $\geq 65$ (HR 11.8 [4.6-30.2]) versus 50-64 years (HR 5.86 [2.27-15.12]). The survival curve revealed that, compared with the diabetes only group, the mortality was increased in the diabetes with comorbidities group $(p=0.009)$ but had was not significantly different from the noncomorbidity group $(p=0.59)$.

\section{Conclusion}

Patients with diabetes had worse outcomes when suffering from COVID-19; however, the outcome was not associated with diabetes itself but with comorbidities. Furthermore, the administration of acarbose could reduce the risk of death in patients with diabetes.

\section{Background}

Corona Virus Disease 2019 (COVID-19) has become an ongoing pandemic and has caused considerable mortality worldwide [1]. Diabetes is a common comorbidity, especially in elderly patients, but the effects of diabetes or antidiabetic medication on the severity and mortality of COVID-19 have not been well described. As of October 27, 2020, more than thirty million COVID-19 cases had been confirmed around the world, and nearly 1 million patients died of COVID-19 (https://www.who.int/emergencies/diseases/novel- 
coronavirus-2019). Well-controlled blood glucose (3.9-10.0 mmol/L) in preexisting diabetes was associated with a significant reduction in the composite adverse outcomes and death of patients with COVID-19 [2]. Patients with diabetes often have several comorbidities, and previous research has revealed that hypertension, chronic obstructive pulmonary disease (COPD), chronic kidney disease (CKD), cardiovascular disease and cerebrovascular disease (CVD) are also associated with worse outcomes in patients suffering from COVID-19 [3-6]. However, few studies have described the outcome of different comorbidity statuses of patients with diabetes after infection with COVID-19. In addition, few studies have focused on whether antidiabetic medication would influence the outcome of patients with preexisting diabetes who suffer from COVID-19. Considering this, we performed a multicenter study to investigate the outcome of different statuses (with or without comorbidity) and antidiabetic medication before admission of patients with diabetes with SARS-CoV-2 infection.

\section{Methods}

\section{Study design and participants}

This is a multicenter, observational, retrospective, real-world study that included adult inpatients from six designated tertiary centers (S1) between January 21 and March 25, 2020. A total of 1422 patients with COVID-19 were screened for this study. All patients were diagnosed with COVID-19 in accordance with WHO interim guidance. Figure 1 shows the patient selection flow for this study.

\section{Data collection}

Epidemiological material, demographic information, clinical data, laboratory parameters, radiographic characteristics, treatment and outcome were extracted from electronic medical records using a standardized data collection form. Major clinical symptoms, vital signs at admission and comorbidities were collected. The treatment data included not only COVID-19 but also diabetes mellitus. The duration from the onset of symptoms to admission, illness severity, intensive care unit (ICU) admission, and length of hospital stay were also recorded. All data were checked by a team of sophisticated physicians.

Diabetes was defined as a history record of diabetes and the use of antidiabetic medication; otherwise, newly diagnosed diabetes was based on the level of fasting plasma glucose (FPG) $(\geq 7.0 \mathrm{mmol} / \mathrm{L})$, random plasma glucose ( $\geq 11.1 \mathrm{mmol} / \mathrm{L})$, glycosylated hemoglobin $(\mathrm{HbA} 1 \mathrm{c}) \geq 6.5 \%$ and classic symptoms of hyperglycemia during hospital stay (as the oral glucose tolerance test may lead to hyperglycemia and then to worsening of a COVID-19 patient's illness, it was not used for diagnosis of diabetes in our study [7]). Hypertension was defined by a history of hypertension, the use of antihypertensive drugs, or the National Heart Lung and Blood Institute criteria [8]. Coronary heart disease was defined by a history of coronary heart disease. CVD was defined by a history of CVD. ARDS was defined according to the Berlin definition [9]. Acute kidney injury (AKI) was diagnosed according to the KDIGO (Kidney Disease: Improving Global Outcomes) clinical practice guidelines [10]. Acute cardiac injury $(\mathrm{ACl})$ was reported if serum levels of myocardial injury biomarkers were higher than the upper limit of normal [2]. The criteria for classification of COVID-19 severity were according to the Diagnosis and 
Treatment Protocol for COVID-19 (Trial Version 7) [11]. We divided the patients into two groups: the nonsevere group (mild and general types) and the severe group (severe and critical types).

\section{Outcomes}

The primary outcome was all-cause mortality after admission. Secondary outcomes were ICU admission and incidence of SARS-CoV-2-related complications, including ARDS, AKI, ACl, secondary infection, shock and hypoproteinemia.

\section{Data analyses}

Continuous variables were described as the mean \pm SD or median (IQR). Categorical variables were calculated as frequencies and percentages with available data. The differences in continuous variables among groups were assessed using the independent sample t-test or one-way ANOVA for normally distributed continuous variables or the Mann-Whitney $\mathrm{U}$ test or Kruskal-Wallis $\mathrm{H}$ test for skewed continuous variables. Pearson's chi-square test and Fisher's exact test were performed for unordered categorical variables. The Mann-Whitney $\mathrm{U}$ test or the Kruskal-Wallis $\mathrm{H}$ test was used for ordered categorical variables. To explore the risk factors associated with mortality, multivariable Cox regression models were performed. The Kaplan-Meier plot was performed to compare the survival probability for the diabetes and nondiabetes groups and among the patients with no comorbidities, only diabetes and diabetes with comorbidities by log-rank test. Additionally, we did not process the missing data. The statistical analyses were conducted with SPSS (version 25.0). A two-sided $p$ value less than 0.05 was considered statistically significant.

\section{Results}

\subsection{Clinical characteristics and laboratory results of 1331 patients with COVID-19 divided into different groups}

The characteristics of this study population at baseline are given in Table 1. The median age was 54 years old (39-64) and 64 years old (56-70) in the nondiabetes and diabetes groups, respectively. Comorbidities such as hypertension ( $55.5 \%$ vs $21.4 \%$ ), coronary heart disease ( $9.9 \%$ vs $3.5 \%)$, CVD (7.3\% vs $2.2 \%)$, and CKD $(4.7 \%$ vs $1.5 \%)$ were significantly more prevalent in the diabetes group. Mean systolic blood pressure (SBP) was higher in the diabetes group. Moreover, decreased blood oxygen saturation (lower than 93\%) occurred more frequently in the diabetes group versus the nondiabetes group (19.8\% vs $19.6 \%)$ on admission. Chest CT scan revealed that the incidence of bilateral lesions was higher ( $94 \%$ vs $80.1 \%$ ) in the diabetes group than in the nondiabetes group.

There were numerous differences in laboratory results between the diabetes group and the nondiabetes group with COVID-19 (Table 2). FPG levels were significantly higher in the diabetes group than in the nondiabetes group, as expected, with higher levels of $\mathrm{HbA1c}$. Patients with diabetes had a higher white blood cell count (WBC), neutrophil count (NEU), neutrophil to lymphocyte ratio (NLR), and C-reactive 
protein (CRP) and a lower lymphocyte count (LY) than the nondiabetic group. These results revealed that diabetes represented more severe inflammation. The percentage of high levels of prothrombin time (PT) and D-dimer among the diabetes group was higher than that among the nondiabetes group. The serum level of albumin (ALB) was lower in the diabetes group than in the nondiabetes group. Meanwhile, urea nitrogen (BUN), a marker of kidney function, was higher in the diabetes group. Nondiabetes participants had significantly lower serum levels of lactate dehydrogenase. Compared with the nondiabetes group, the diabetes group had higher levels of total cholesterol $(\mathrm{TCH})$ and lower high-density lipoprotein cholesterol (HDL-C).

In addition, a between-group comparison with only the diabetes group was performed. The baseline characteristics and radiological findings are also summarized in Table 1. Patients with diabetes with comorbidities were the oldest among the three groups. There was a significant difference in blood oxygen saturation and respiratory rate among the three groups but no significant differences in the comparison of the noncomorbidity group and only diabetes group or the comparison of the diabetes only group and diabetes with comorbidities group. Chest CT scans indicated that the diabetes only group had more incidences of bilateral lesions than the noncomorbidity group.

Although there were numerous differences in laboratory findings among the noncomorbidity group, diabetes only group and diabetes with comorbidities group (Table 2), only ten items had statistical significance between the noncomorbidity group and diabetes only group, including ALB, sodium, BUN, CRP, and $\mathrm{HDL}-\mathrm{C}$, as well as FPG and $\mathrm{HbA1c}$, as expected. These results combined with oxygen saturation indicated that there was no difference in cardiac, liver, lung and coagulation function between the groups.

FPG and $\mathrm{HbA} 1 \mathrm{c}$ in the diabetes only group and diabetes with comorbidities group were almost at the same level. Compared with the diabetes only group, the diabetes with comorbidities group had a lower LY and a higher NLR and CRP, which represented a more severe inflammatory response.

\subsection{Treatment and outcome of 1331 patients with COVID-19 divided into different groups}

As shown in Table 3, 1223 of the 1331 patients (91.9\%) were discharged from the hospital; the rate of mortality of the diabetes group was higher than that of the nondiabetes group (13.6\% vs $7.2 \%)$. KaplanMeier survival analysis for all-cause mortality in patients with COVID-19 is shown in Figure 2. The overall survival rate was significantly lower in the diabetes group (log-rank $p<0.01$, Figure $2 \mathrm{~A}$ ). Compared with nondiabetes patients, more patients with diabetes reported severe cases (34.6\% vs $21.7 \%$ ). The diabetes group had a higher rate of ARDS ( $11 \%$ vs $5.7 \%$ ) and hypoproteinemia ( $15 \%$ vs $6.5 \%$ ).

The treatment and primary outcome of the noncomorbidity group and diabetes only group were not different (Table 3), and the results for all-cause mortality were similar in both groups (log-rank $p=0.59$ ) (Figure 2B). Regarding the secondary endpoint, there was no difference between the groups except for hypoproteinemia (5.0\% vs $16.9 \%$ ). Likewise, there was a similar frequency of COVID-19 pharmacological therapy in the diabetes only patients versus diabetes with comorbidities patients; however, the latter was 
more likely to receive mechanical ventilation ( $10.8 \%$ vs $18.3 \%)$, had a higher incidence of mortality ( $4.6 \%$ vs $18.3 \%$ ), greater likelihood of shock ( 0 vs $1.6 \%$ ) and more severe cases $(21.5 \%$ vs $41.3 \%)$.

\subsection{Clinical characteristics and laboratory results of diabetic survivors and nonsurvivors with COVID-19}

Diabetic survivors $(n=165)$ and nonsurvivors $(n=26)$ shared basic characteristics except for decreased blood oxygen saturation (10.9\% vs $26.9 \%$ ) and rapid breathing (18.2\% vs $26.9 \%)$, which were more frequent in nonsurvivors (S2), indicating that the latter had severe lung dysfunction. There were numerous differences in laboratory results between diabetic survivors and nonsurvivors with COVID-19 that reflected the functions of different organs and systems (S2). Diabetic nonsurvivors had higher WBC, NEU, NLR, CRP, and IL-6 and lower LY, reflecting that mortality patients had severe inflammatory responses. Serum levels of PT, D-dimer, ALT, AST, BUN, creatinine, CK, and LDH were all significantly higher in nonsurvivors, which reflected more severe coagulation, liver, kidney, and cardiac dysfunction. Diabetic nonsurvivors reported higher average FPG compared with survivors.

\subsection{Treatment and outcome of diabetic survivors and nonsurvivors with COVID-19}

Undoubtedly, higher proportions of complications, including ARDS (3.0 vs $61.5 \%)$, ACl ( $5.5 \%$ vs $26.9 \%$ ), shock (0 vs $11.5 \%)$, secondary infection ( $6.1 \%$ vs $46.2 \%])$, AKI ( $0.6 \%$ vs $7.7 \%)$ and coagulopathy ( $15.8 \%$ vs $38.5 \%$ ), were found in nonsurvivors (Table 5). Likewise, the nonsurvivor group had a greater incidence of severe cases (33.7\% vs $100 \%$ ) and ICU admission (6.7\% vs $42.3 \%$ ) and was more likely to receive corticosteroids (33.3\% vs $73.1 \%$ ). There was a significantly lower frequency of hypoglycemic medication in diabetic nonsurvivors versus diabetic survivors, including metformin (30.9\% vs $11.5 \%)$, sulfonylurea ( $21.8 \%$ vs $3.8 \%$ ) and acarbose ( $45.5 \%$ vs $7.7 \%)$, which might be related to controlled blood glucose.

\subsection{Clinical characteristics, laboratory results, treatment and outcome of patients with diabetes with COVID-19 using metformin and matched nonmetformin users}

Of 191 patients with diabetes with COVID-19, 54 cases were using metformin, and after sex and age matching, there were 50 patients using metformin and 50 sex-and age-matched nonmetformin users. The frequency of fever ( $54 \%$ vs $78 \%$ ) and fatigue ( $38 \%$ vs $18 \%$ ) showed significant differences in clinical characteristics between patients with diabetes with COVID-19 using metformin and matched nonmetformin users (S3). Laboratory findings (Table 6) revealed that metformin users had lower levels of LDH and FPG; however, the distribution of glucose was similar. The results that referred to liver, kidney, cardiac, coagulation and inflammatory response function were not statistically significant. The primary outcome and secondary outcome of patients who used metformin were comparable to matched nonmetformin users (Table 7). The former group showed a higher need for antivirals ( $98 \%$ vs $84 \%$ ) and antibiotics (90\% vs $74 \%$ ). Insulin ( $52.0 \%$ vs $20 \%$ ), sulfonylurea ( $36.0 \%$ vs $2 \%$ ), acarbose $(56.0 \%$ vs $6 \%$ ), and thiazolidinedione ( $12 \%$ vs 0 ) were also applied significantly more frequently to the individuals using metformin.

3.6 Clinical characteristics, laboratory results, treatment and outcome of patients with diabetes with COVID-19 using acarbose and matched nonacarbose users 
Of 191 patients with diabetes with COVID-19, 77 cases were treated with acarbose, and after sex and age matching, there were 46 patients treated with acarbose and 46 sex- and age-matched nonacarbose users. S3 shows that the length of symptom onset to hospital admission was longer in the acarbose group than in the matched nonacarbose group, which indicated that the symptoms in the former patients might be relatively mild. Notably, some inflammatory response-related laboratory results, such as WBC, NLR, and CRP, were significantly lower in the acarbose group (Table 6). Furthermore, these differences were not related to glucose control, as the serum level of glucose in both groups was comparable.

The mortality rate (2.2\% vs $26.1 \%$ ) was lower in the acarbose group (Table 7), as were the rates of ARDS $(2.2 \%$ vs $17.4 \%$ ) and shock ( $2.2 \%$ vs $21.7 \%$ ). At the same time, patients who were treated with acarbose indicated a lower need for treatment with corticosteroids ( $26.1 \%$ vs $47.8 \%)$, immunoglobin $(23.9 \%$ vs $47.8 \%$ ), mechanical ventilation (6.5\% vs $21.7 \%$ ), and insulin ( $50.0 \%$ vs $84.8 \%$ ).

\subsection{Independent risk factors for mortality of patients with COVID-19}

Among the 1131 included patients, multivariable Cox regression (Table 8) showed that male (hazard ratio [HR] 2.59, 95\% Cl 1.63-3.99), hypertension (HR 1.75, 95\% Cl 1.18-2.6), CKD (HR 4.55, 95\% Cl 2.52-8.20), and CVD (HR 2.35, 95\% Cl 1.27-4.33) were risk factors for COVID-19 mortality. Age was also a risk factor for COVID mortality. However, diabetes alone was not an independent risk factor for mortality in patients with COVID-19.

\section{Discussion}

A number of studies have demonstrated that patients with diabetes have a higher risk of mortality from COVID, as well as a greater risk of developing more severe cases $[4,7,12,13]$. Guo et al. reported that diabetes was a risk factor for the progression and prognosis of COVID-19 [13]. However, Shi et al. pointed out that diabetes was not independently associated with COVID mortality, while commonalities, such as hypertension and cardiovascular disease, played more important roles in contributing to the in-hospital death of patients with COVID-19, which was relatively limited in size [14]. In this study, which had relatively rich clinical data, we found that diabetes alone was not an independent risk factor for in-hospital mortality from COVID-19, but comorbidities such as hypertension and CKD were risk factors; this result was consistent with a previous study [14]. Partially consistent with previous studies, our study found that compared with nondiabetic patients, patients with diabetes with COVID-19 were older, had worse outcomes, including a higher rate of mortality, severe cases and ARDS, and presented severe inflammatory response, lung and coagulation dysfunction $[7,13,15]$. Additionally, patients with diabetes had increased levels of urea nitrogen and decreased levels of albumin. These abnormalities indicated that COVID-19 may be associated with progressive organ injury in patients with diabetes. Preexisting hypertension, CHD, CVD, and CKD had higher frequencies in the diabetic group. Recent studies reported that patients with cardiovascular hypertension, CKD, and CVD were more likely to develop severe cases $[4,6,16]$, so we compared patients with diabetes and COVID without comorbidity and patients with COVID without any comorbidity to identify whether diabetes without comorbidity was a risk factor for COVID-19. In our study, there was no difference in the outcome between the noncomorbidity group and the diabetes only group. 
Shi et al. reported that even though patients with COVID-19 with diabetes had worse outcomes, it was not independently associated with in-hospital death, which was consistent with our results [16]. In addition, most laboratory results were comparable between the noncomorbidity group and the diabetes only group, except for CRP, albumin, sodium, urea nitrogen, HDL-C and, of course, blood glucose. CRP is an inflammatory biomarker that is related to glucose homoeostasis, obesity and atherosclerosis [17] and was independently related to insulin sensitivity [18]. In addition, insulin resistance was a main characteristic of type 2 diabetes; since CRP was related to the chronic inflammatory situation, and the levels of WBC, NEU, and $L Y$, which reflected the acute infection with the disease pathogen, were not statistically significant, we inferred that diabetes itself did not increase the degree of inflammation after SARS-CoV-2 infection.

Patients with diabetes with comorbidities were more seriously ill when compared with the diabetes only group and noncomorbidity group. The mortality was higher in the diabetes with comorbidities group, but the difference between both diabetes groups had no relation to FPG because the median FPG in both diabetes groups was comparable. Patients with diabetes with comorbidity were 10 years older than patients who had no comorbidity except diabetes; furthermore, age $\geq 65$ years was associated with a greater risk of death [4]. As described above, patients with hypertension and CVD were more likely to develop severe cases [4]. Furthermore, our analysis indicated that age, hypertension, CKD, and CVD were risk factors for COVID-19 mortality. Since the diabetes with comorbidities group had a higher prevalence of hypertension, CKD and CVD, there was no doubt that patients with diabetes with comorbidities had worse outcomes.

One unanticipated result was that acarbose, not metformin, could improve prognosis through a decrease in the degree of inflammation, which was independent of the blood glucose level. In addition, acarbose accounted for $97 \%$ of the glycosidase inhibitors used. Feng et al. reported that acarbose could effectively block the metastasis of enterovirus 71 (EV71) from the intestine to the whole body [19]. EV71 is one of the main causes of hand-foot-and-mouth disease (HFMD), and its infection relies on the interaction of the canyon region of its virion surface and the glycosylation of the SCARB2 protein, which is the cellular receptor of EV71 infection. Dang et al. found that acarbose not only inhibited cellular receptors of various glycosylated viruses but also competitively blocked the canyon region of the EV71 virion surface [20], blocking the metastasis of EV71 from the intestine. Angiotensin converting enzyme II (ACE2) is a SARSCoV-2 cell entry receptor [21], and glycosylation sites play an important role in the combination of SARSCoV-2 and its receptor [22-23]. Chloroquine was reported to block SARS-CoV-2 infection by interfering with the glycosylation of cellular receptors [24]. As previously stated, acarbose inhibited the glycosylation of EV71 receptors; additionally, patients with diabetes with COVID-19 who were treated with acarbose had better outcomes than patients who were not treated, suggesting that acarbose could improve the prognosis of COVID-19 infection by inhibiting the glycosylation of ACE2. In addition, compared to the nonacarbose group, the acarbose group had lower WBC, NLR, and CRP levels, indicating a decreased inflammatory response and further supporting the anti-SARS-CoV-2 function of acarbose. Furthermore, a 
previous study showed that acarbose could change the gut microbiota and then beneficially regulate the body's immune function [25]. A recent study revealed that fetal microbiome changes occurred in patients with COVID-19, characterized by depletion of beneficial commensals and enrichment of opportunistic pathogens [26]. Therefore, we inferred that acarbose might increase the baseline abundance of microbiota that had inversely correlated with COVID-19.

As previous studies reported that metformin has multiple additional health benefits in patients with diabetes [27], we anticipated that metformin would improve prognosis after COVID-19 infection; however, the results were unexpected. Scanning the literature, we found that metformin improves ACE2 stability through AMPK [28], which means that metformin may increase ACE2 availability. In addition, the median level of FPG was higher in metformin users than in nonusers, as a previous study reported that improving glycemic control substantially reduced the risk of mortality from COVID-19.

The study has some limitations. First, due to the retrospective and multiple-center study design, some information, such as patients' exposure history, diabetes medication and several laboratory items, was not available for all patients. There could be assay variability in different centers. Second, samples were only from Hubei Province, China; thus, more studies in other regions, even other countries, might obtain more comprehensive insight into COVID-19. However, this study is one of the largest retrospective and multicenter studies among patients with COVID-19. Additionally, this study is one of the first to investigate the influence of diabetes medications in patients with diabetes with COVID-19. The relatively abundant clinical data and numerous events also strengthen the results. The conclusion will help clinicians identify high-risk patients and choose suitable diabetes medication for patients with diabetes.

\section{Conclusion}

In conclusion, patients with diabetes had worse outcomes when suffering from COVID-19; however, the outcome was not related to diabetes itself but to comorbidities such as hypertension, CKD and CVD. Furthermore, the administration of acarbose could reduce the risk of death, ARDS, and shock in patients with diabetes.

\section{Abbreviations}

AKI, acute kidney injury;

ARDS, acute respiratory distress syndrome;

CKD, chronic kidney disease;

COPD, chronic obstructive pulmonary disease; 
COVID-19, coronavirus disease 2019;

CVD, cerebrovascular disease;

DM, diabetes mellitus;

FPG, fasting plasma glucose;

$H R$, hazard ratio;

ICU, intensive care unit;

KDIGO, Kidney Disease: Improving Global Outcomes;

MODS, multiple organ dysfunction syndrome;

SARS-CoV-2, severe acute respiratory syndrome coronavirus-2.

\section{Declarations}

\section{Acknowledgements}

We acknowledge all health-care workers involved in the diagnosis and treatment of patients in Hubei Province.

\section{Authors' Contributions}

$\mathrm{HL}$ and JM conceptualized the design of the study, had full access to all of the data in the study and took responsibility for the integrity of the data and the accuracy of the data analysis. SL and WH drafted the manuscript. ZL and SL did the analysis. QC, YX, WH, CL, LW, ZC, LR, JY and MY collected the data, ZL, JY, SC and JT recorded the data.

\section{Funding}

This study was supported by the National Natural Science Foundation of China (Grant 81670815), Special Fund for Innovation Strategy of Science and Technology plan of Guangdong province (Grant 2019A030317011) and Guangdong Basic and Applied Basic Research Foundation (Grant 2020A1515010124).

\section{Availability of data and material}


The datasets used and/or analysed during the current study are available from the corresponding author on reasonable request.

\section{Ethics approval and consent to participate}

This case series' study was approved by institutional Ethics Commission of Ningbo First Hospital of Zhejiang University , institutional Ethics Commission of Hubei No.3 People's Hospital of Jianghan University, institutional Ethics Commission of People's Hospital of Jiayu County, institutional Ethics Commission of the First Hospital of Jingzhou, institutional Ethics Commission of the Fifth Affiliated Hospital of Sun Yat-sen University. Written informed consent was waived by the Ethics Commission of the hospitals for emerging infectious diseases.

\section{Consent for publication}

Not applicable.

\section{Competing interests}

The authors declare that they have no competing interests.

\section{References}

[1]. $\quad \mathrm{Xu}, \mathrm{X} . ;$ Ong, Y. K.; Wang, Y., Role of adjunctive treatment strategies in COVID-19 and a review of international and national clinical guidelines. Mil Med Res 2020, 7 (1), 22.

[2]. Zhu, L.; She, Z. G.; Cheng, X.; Qin, J. J.; Zhang, X. J.; Cai, J.; Lei, F.; Wang, H.; Xie, J.; Wang, W.; Li, H.; Zhang, P.; Song, X.; Chen, X.; Xiang, M.; Zhang, C.; Bai, L.; Xiang, D.; Chen, M. M.; Liu, Y.; Yan, Y.; Liu, M.; Mao, W.; Zou, J.; Liu, L.; Chen, G.; Luo, P.; Xiao, B.; Zhang, C.; Zhang, Z.; Lu, Z.; Wang, J.; Lu, H.; Xia, X.; Wang, D.; Liao, X.; Peng, G.; Ye, P.; Yang, J.; Yuan, Y.; Huang, X.; Guo, J.; Zhang, B. H.; Li, H., Association of Blood Glucose Control and Outcomes in Patients with COVID-19 and Pre-existing Type 2 Diabetes. Cell Metab 2020, 31 (6), 1068-1077 e3.

[3]. Zhou, F.; Yu, T.; Du, R.; Fan, G.; Liu, Y.; Liu, Z.; Xiang, J.; Wang, Y.; Song, B.; Gu, X.; Guan, L.; Wei, Y.; Li, H.; Wu, X.; Xu, J.; Tu, S.; Zhang, Y.; Chen, H.; Cao, B., Clinical course and risk factors for mortality of adult inpatients with COVID-19 in Wuhan, China: a retrospective cohort study. Lancet 2020, 395 (10229), 10541062.

[4]. Wu, C.; Chen, X.; Cai, Y.; Xia, J.; Zhou, X.; Xu, S.; Huang, H.; Zhang, L.; Zhou, X.; Du, C.; Zhang, Y.; Song, J.; Wang, S.; Chao, Y.; Yang, Z.; Xu, J.; Zhou, X.; Chen, D.; Xiong, W.; Xu, L.; Zhou, F.; Jiang, J.; Bai, C.; Zheng, J.; Song, Y., Risk Factors Associated With Acute Respiratory Distress Syndrome and Death in 
Patients With Coronavirus Disease 2019 Pneumonia in Wuhan, China. JAMA Intern Med 2020, 180 (7), 934-943.

[5]. Matthay, M. A.; Aldrich, J. M.; Gotts, J. E., Treatment for severe acute respiratory distress syndrome from COVID-19. Lancet Respir Med 2020, 8 (5), 433-434.

[6]. Ji, H. L.; Zhao, R.; Matalon, S.; Matthay, M. A., Elevated Plasmin(ogen) as a Common Risk Factor for COVID-19 Susceptibility. Physiol Rev 2020, 100 (3), 1065-1075.

[7]. Yan, Y.; Yang, Y.; Wang, F.; Ren, H.; Zhang, S.; Shi, X.; Yu, X.; Dong, K., Clinical characteristics and outcomes of patients with severe covid-19 with diabetes. BMJ Open Diabetes Res Care 2020, 8 (7).

[8]. Chobanian, A. V.; Bakris, G. L.; Black, H. R.; Cushman, W. C.; Green, L. A.; Izzo, J. L., Jr.; Jones, D. W.; Materson, B. J.; Oparil, S.; Wright, J. T., Jr.; Roccella, E. J., Seventh report of the Joint National Committee on Prevention, Detection, Evaluation, and Treatment of High Blood Pressure. Hypertension 2003, 42 (6), 1206-52.

[9]. Thompson, B. T.; Chambers, R. C.; Liu, K. D., Acute Respiratory Distress Syndrome. N Eng/ J Med 2017, $377(6), 562-572$.

[10]. Khwaja, A., KDIGO clinical practice guidelines for acute kidney injury. Nephron Clin Pract 2012, 120 (4), c179-84.

[11]. National Health Commission SAoTCM. Diagnosis and treatment of COVID-19 (trial version 7). http://www.gov.cn/zhengce/zhengceku/2020-03/04/content_5486705.htm. Accessed 3 Mar 2020.

[12]. Hussain, A.; Ali, I.; Hassan, Z., People with Diabetes Mellitus: Soft target for COVID-19 infection. Pak J Med Sci 2020, 36 (COVID19-S4), S3-S5.

[13]. Guo, W.; Li, M.; Dong, Y.; Zhou, H.; Zhang, Z.; Tian, C.; Qin, R.; Wang, H.; Shen, Y.; Du, K.; Zhao, L.; Fan, H.; Luo, S.; Hu, D., Diabetes is a risk factor for the progression and prognosis of COVID-19. Diabetes Metab Res Rev 2020, e3319.

[14]. Shi, Q.; Zhang, X.; Jiang, F.; Zhang, X.; Hu, N.; Bimu, C.; Feng, J.; Yan, S.; Guan, Y.; Xu, D.; He, G.; Chen, C.; Xiong, X.; Liu, L.; Li, H.; Tao, J.; Peng, Z.; Wang, W., Clinical Characteristics and Risk Factors for Mortality of COVID-19 Patients With Diabetes in Wuhan, China: A Two-Center, Retrospective Study. Diabetes Care 2020, 43 (7), 1382-1391.

[15]. Bornstein, S. R.; Rubino, F.; Khunti, K.; Mingrone, G.; Hopkins, D.; Birkenfeld, A. L.; Boehm, B.; Amiel, S.; Holt, R. I.; Skyler, J. S.; DeVries, J. H.; Renard, E.; Eckel, R. H.; Zimmet, P.; Alberti, K. G.; Vidal, J.; Geloneze, B.; Chan, J. C.; Ji, L.; Ludwig, B., Practical recommendations for the management of diabetes in patients with COVID-19. Lancet Diabetes Endocrinol 2020, 8 (6), 546-550. 
[16]. Shi, S.; Qin, M.; Cai, Y.; Liu, T.; Shen, B.; Yang, F.; Cao, S.; Liu, X.; Xiang, Y.; Zhao, Q.; Huang, H.; Yang, B.; Huang, C., Characteristics and clinical significance of myocardial injury in patients with severe coronavirus disease 2019. Eur Heart J 2020, 41 (22), 2070-2079.

[17]. Sjöholm, A.; Nyström, T., Endothelial inflammation in insulin resistance. Lancet 2005, 365 (9459), $610-2$.

[18]. Festa, A.; D'Agostino, R., Jr.; Howard, G.; Mykkänen, L.; Tracy, R. P.; Haffner, S. M., Chronic subclinical inflammation as part of the insulin resistance syndrome: the Insulin Resistance Atherosclerosis Study (IRAS). Circulation 2000, 102 (1), 42-7.

[19]. Feng, Q.; Zhou, H.; Zhang, X.; Liu, X.; Wang, J.; Zhang, C.; Ma, X.; Quan, C.; Zheng, Z., Acarbose, as a potential drug, effectively blocked the dynamic metastasis of EV71 from the intestine to the whole body. Infect Genet Evol 2020, 81, 104210.

[20]. Dang, M.; Wang, X.; Wang, Q.; Wang, Y.; Lin, J.; Sun, Y.; Li, X.; Zhang, L.; Lou, Z.; Wang, J.; Rao, Z., Molecular mechanism of SCARB2-mediated attachment and uncoating of EV71. Protein Cell 2014, $5(9)$, 692-703.

[21]. Zhou, P.; Yang, X. L.; Wang, X. G.; Hu, B.; Zhang, L.; Zhang, W.; Si, H. R.; Zhu, Y.; Li, B.; Huang, C. L.; Chen, H. D.; Chen, J.; Luo, Y.; Guo, H.; Jiang, R. D.; Liu, M. Q.; Chen, Y.; Shen, X. R.; Wang, X.; Zheng, X. S.; Zhao, K.; Chen, Q. J.; Deng, F.; Liu, L. L.; Yan, B.; Zhan, F. X.; Wang, Y. Y.; Xiao, G. F.; Shi, Z. L., A pneumonia outbreak associated with a new coronavirus of probable bat origin. Nature 2020, 579 (7798), 270-273.

[22]. Yan, R.; Zhang, Y.; Li, Y.; Xia, L.; Guo, Y.; Zhou, Q., Structural basis for the recognition of SARS-CoV-2 by full-length human ACE2. Science 2020, 367 (6485), 1444-1448.

[23]. Watanabe, Y.; Allen, J. D.; Wrapp, D.; McLellan, J. S.; Crispin, M., Site-specific glycan analysis of the SARS-CoV-2 spike. Science 2020, 369 (6501), 330-333.

[24]. Alifano, M.; Alifano, P.; Forgez, P.; lannelli, A., Renin-angiotensin system at the heart of COVID-19 pandemic. Biochimie 2020, 174, 30-33.

[25]. Gu, Y.; Wang, X.; Li, J.; Zhang, Y.; Zhong, H.; Liu, R.; Zhang, D.; Feng, Q.; Xie, X.; Hong, J.; Ren, H.; Liu, W.; Ma, J.; Su, Q.; Zhang, H.; Yang, J.; Wang, X.; Zhao, X.; Gu, W.; Bi, Y.; Peng, Y.; Xu, X.; Xia, H.; Li, F.; Xu, X.; Yang, H.; Xu, G.; Madsen, L.; Kristiansen, K.; Ning, G.; Wang, W., Analyses of gut microbiota and plasma bile acids enable stratification of patients for antidiabetic treatment. Nat Commun 2017, 8(1), 1785.

[26]. Zuo, T.; Zhang, F.; Lui, G. C. Y.; Yeoh, Y. K.; Li, A. Y. L.; Zhan, H.; Wan, Y.; Chung, A. C. K.; Cheung, C. P.; Chen, N.; Lai, C. K. C.; Chen, Z.; Tso, E. Y. K.; Fung, K. S. C.; Chan, V.; Ling, L.; Joynt, G.; Hui, D. S. C.; Chan, F. K. L.; Chan, P. K. S.; Ng, S. C., Alterations in Gut Microbiota of Patients With COVID-19 During Time of Hospitalization. Gastroenterology 2020, 159 (3), 944-955 e8. 
[27]. Au Yeung, S. L.; Luo, S.; Schooling, C. M., The impact of GDF-15, a biomarker for metformin, on the risk of coronary artery disease, breast and colorectal cancer, and type 2 diabetes and metabolic traits: a Mendelian randomisation study. Diabetologia 2019, 62 (9), 1638-1646.

[28]. Zhang, J.; Dong, J.; Martin, M.; He, M.; Gongol, B.; Marin, T. L.; Chen, L.; Shi, X.; Yin, Y.; Shang, F.; Wu, Y.; Huang, H. Y.; Zhang, J.; Zhang, Y.; Kang, J.; Moya, E. A.; Huang, H. D.; Powell, F. L.; Chen, Z.;

Thistlethwaite, P. A.; Yuan, Z. Y.; Shyy, J. Y., AMP-activated Protein Kinase Phosphorylation of AngiotensinConverting Enzyme 2 in Endothelium Mitigates Pulmonary Hypertension. Am J Respir Crit Care Med 2018, 198 (4), 509-520.

\section{Tables}

Table 1. Baseline characteristics of 1331 COVID-19 patients divided into different groups 


\begin{tabular}{|c|c|c|c|c|c|c|c|c|}
\hline & $\begin{array}{c}\text { Total } \\
(n=1331)\end{array}$ & $\begin{array}{c}\text { Non- } \\
\text { diabetes } \\
(\mathrm{n}=1140)\end{array}$ & $\begin{array}{l}\text { Diabetes } \\
(n=191)\end{array}$ & $\begin{array}{c}P^{\#} \\
\text { value }\end{array}$ & $\begin{array}{c}\text { Non- } \\
\text { comorbidity } \\
(n=779)\end{array}$ & $\begin{array}{l}\text { Diabetes } \\
\text { only } \\
(n=65)\end{array}$ & $\begin{array}{c}\text { Diabetes } \\
\text { with } \\
\text { comorbidities } \\
(n=126)\end{array}$ & $P^{\dagger}$ value \\
\hline \multicolumn{9}{|l|}{ Demographic } \\
\hline Male, \% & 673(50.6) & $565(49.6)$ & 108(56.5) & 0.074 & $369(47.4)$ & $40(61.5)$ & $68(54.0)$ & 0.046 \\
\hline Age, years & $\begin{array}{c}56.0 \\
(42.0-65.0)\end{array}$ & $\begin{array}{c}54.0(39.0- \\
64.0)\end{array}$ & $\begin{array}{l}64.0 \\
(56.0- \\
70.0)\end{array}$ & $<0.001$ & $\begin{array}{c}48.0 * * * \\
(36.0-60.0)\end{array}$ & $\begin{array}{l}57.0 \\
(50.0- \\
64.0)\end{array}$ & $\begin{array}{c}67.0 * * * \\
(59.0-72.0)\end{array}$ & $<0.001$ \\
\hline $18-49$ & $500(37.6)$ & $477(41.8)$ & $23(12.0)$ & $<0.001$ & $\begin{array}{c}415 \\
(53.3)^{* * *}\end{array}$ & $16(24.6)$ & $7(5.6)^{* * *}$ & $<0.001^{\mathrm{a}}$ \\
\hline $50-64$ & $458(34.4)$ & $382(33.5)$ & $76(39.8)$ & & $253(32.5)$ & $34(52.3)$ & $42(33.3)$ & \\
\hline$\geq 65$ & $373(28.0)$ & $281(24.6)$ & $92(48.2)$ & & $111(14.2)$ & $15(23.1)$ & $77(61.1)$ & \\
\hline Wuhan exposure & $1190(89.4)$ & $1008(88.4)$ & $182(95.3)$ & 0.004 & $686(88.3)$ & $61(95.3)$ & $120(95.2)$ & 0.018 \\
\hline Current smoking, \% & $107(8.1)$ & $93(8.2)$ & $14(7.4)$ & 0.736 & $55(7.2)$ & $3(4.7)$ & $11(8.9)$ & 0.149 \\
\hline Onset of symptom, $\mathrm{d}$ & $\begin{array}{c}8.0(5.0- \\
14.0)\end{array}$ & $\begin{array}{c}8.0(5.0- \\
14.0)\end{array}$ & $\begin{array}{c}10.0(6.0- \\
13.0)\end{array}$ & 0.217 & $\begin{array}{c}8.0(4.8- \\
14.0)\end{array}$ & $\begin{array}{c}10.0(6.5- \\
16.5)\end{array}$ & $\begin{array}{c}10.0(5.8- \\
12.0)\end{array}$ & 0.109 \\
\hline
\end{tabular}

\section{Symptoms}

\begin{tabular}{|c|c|c|c|c|c|c|c|c|}
\hline Fever & $955(71.8)$ & $823(72.2)$ & $132(69.1)$ & 0.381 & $570(73.2)$ & $46(70.8)$ & $86(68.3)$ & 0.496 \\
\hline Dyspnea & $270(20.3)$ & $227(19.9)$ & $43(22.5)$ & 0.408 & 135(17.3) & $9(13.8)$ & $34(27.0)$ & 0.021 \\
\hline Cough & 777(58.4) & $660(57.9)$ & $117(61.3)$ & 0.383 & 433(55.6) & $46(70.8)$ & $71(56.7)$ & 0.060 \\
\hline Sputum production & $138(10.4)$ & 126(11.1) & $12(6.3)$ & 0.045 & $84(10.8)$ & $4(6.2)$ & $8(6.3)$ & 0.175 \\
\hline Hemoptysis & $3(0.2)$ & $3(0.3)$ & $0(0.0)$ & 1.000 & $1(0.1)$ & $0(0.0)$ & $0(0.0)$ & 0.885 \\
\hline Fatigue & $362(27.2)$ & $306(26.8)$ & $56(29.3)$ & 0.476 & $212(27.2)$ & $16(24.6)$ & $40(31.7)$ & 0.489 \\
\hline Headache & $47(3.5)$ & $44(3.9)$ & $3(1.6)$ & 0.169 & $29(3.7)$ & $3(4.6)$ & $0(0.0)$ & 0.010 \\
\hline Nausea or vomiting & $44(3.3)$ & $39(3.4)$ & $5(2.6)$ & 0.566 & $25(3.2)$ & $2(3.1)$ & $3(2.4)$ & 0.939 \\
\hline Diarrhea & $112(8.4)$ & $97(8.5)$ & $15(7.9)$ & 0.763 & $63(8.1)$ & $9(13.8)$ & $6(4.8)$ & 0.091 \\
\hline Temperature, ${ }^{\circ} \mathrm{C}$ & $\begin{array}{c}36.8(36.5- \\
37.5)\end{array}$ & $\begin{array}{c}36.8(36.5- \\
37.5)\end{array}$ & $\begin{array}{l}36.7(36.4- \\
37.4)\end{array}$ & 0.018 & $\begin{array}{c}36.8(36.5- \\
37.5)\end{array}$ & $\begin{array}{c}\text { 36.8(36.5- } \\
37.6)\end{array}$ & $\begin{array}{c}36.6(36.4- \\
37.3)\end{array}$ & 0.018 \\
\hline$\geq 39$ & $30(2.4)$ & $25(2.3)$ & $5(2.7)$ & 0.980 & $16(2.2)$ & $2(3.1)$ & $3(2.4)$ & 0.889 \\
\hline $\begin{array}{l}\text { Pulse } \geq 100 \text { beats } \\
\text { per min }\end{array}$ & $244(18.5)$ & 209 (18.5) & 35 (18.3) & 0.955 & $125(16.1)$ & $12(18.5)$ & $23(18.30)$ & 0.761 \\
\hline $\begin{array}{l}\text { Blood oxygen } \\
\text { saturation }<93 \%\end{array}$ & $124(11.1)$ & $92(9.6)$ & $32(19.8)$ & $<0.001$ & $43(6.5)$ & 7 (12.5) & $25(23.6)$ & $<0.001$ \\
\hline $\begin{array}{l}\text { Respiratory rate } \\
>24 \text { breaths/min }\end{array}$ & $71(5.4)$ & $56(5.0)$ & $15(7.9)$ & 0.105 & $27(3.5)$ & $2(3.1)$ & $13(10.3)$ & 0.002 \\
\hline $\begin{array}{l}\text { Mean systolic blood } \\
\text { pressure, } \mathrm{mmHg}\end{array}$ & $\begin{array}{l}\text { 125(120- } \\
135)\end{array}$ & $\begin{array}{c}124(119- \\
135)\end{array}$ & $\begin{array}{l}128(120- \\
140)\end{array}$ & 0.001 & $\begin{array}{l}\text { 121(118- } \\
131)\end{array}$ & $\begin{array}{c}127(120- \\
133)\end{array}$ & $\begin{array}{l}130(120- \\
140)\end{array}$ & $<0.001$ \\
\hline $\begin{array}{l}\text { Mean diastolic blood } \\
\text { pressure, } \mathrm{mmHg}\end{array}$ & $\begin{array}{l}80.0(74.0- \\
85.0)\end{array}$ & $\begin{array}{c}80.0(74.0- \\
85.0)\end{array}$ & $\begin{array}{c}80.0(74.0- \\
85.0)\end{array}$ & 0.777 & $\begin{array}{c}80.0(73.0- \\
83.0)\end{array}$ & $\begin{array}{l}80.0(72.5- \\
85.0)\end{array}$ & $\begin{array}{l}80.0(74.0- \\
84.3)\end{array}$ & 0.550 \\
\hline
\end{tabular}

\section{Radiological}

findings

Ground glass

opacity

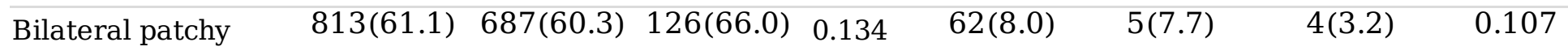


shadowing

\begin{tabular}{llllllll}
\hline Bilateral lesions $\quad 962(82.1)$ & $805(80.1)$ & $157(94.0)<0.001$ & $524(76.2)^{*}$ & $53(91.4)$ & $104(95.4)$ & $<0.001$
\end{tabular}

\section{Comorbidity}

Hypertension

$350(26.3) 244(21.4) \quad 106(55.5)<0.001$

CHD

$59(4.4) \quad 40(3.5) \quad 19(9.9) \quad<0.001$

Chronic liver

$20(1.5) \quad 18(1.6) \quad 2(1.0) \quad 0.812$

disease

\begin{tabular}{lllllllll}
\hline CVD & $39(2.9)$ & $25(2.2)$ & $14(7.3)$ & $<0.001$ & - & - & - & - \\
CKD & $26(2.0)$ & $17(1.5)$ & $9(4.7)$ & 0.007 & - & - & - & - \\
\hline COPD & $10(0.8)$ & $10(0.9)$ & $0(0.0)$ & 0.397 & - & - & - & - \\
\hline
\end{tabular}

Datas are expressed as $\mathrm{n}(\%)$, mean \pm SD or median (IQR). Pvalues were calculated by T Test, MannWhitney $U$ test, $x^{2}$ test, Fisher's exact test, One-Way ANOVA, Kruskal-Wallis H test as appropriate. ${ }^{a}$ MannWhitney U test comparing all subcategories. "Comparing groups of diabetes and non-diabetes patients; †Comparing groups of non-comorbidity, only diabetes and diabetes with comorbidities. Compared with diabetes only group, ${ }^{\star} P<0.05, * \star P<0.05, * \star \star P<0.001$. CHD, Coronary heart disease; CVD, cerebrovascular disease; CKD, Chronic kidney disease; COPD, chronic obstructive pulmonary disease.

Table 2. Laboratory results of 1331 COVID-19 patients divided into different groups 


\begin{tabular}{|c|c|c|c|c|c|c|c|c|}
\hline & $\begin{array}{c}\text { Total } \\
(n=1331)\end{array}$ & $\begin{array}{c}\text { Non- } \\
\text { diabetes } \\
(n=1140)\end{array}$ & $\begin{array}{l}\text { Diabetes } \\
(n=191)\end{array}$ & $P^{\#}$ value & $\begin{array}{c}\text { Non- } \\
\text { comorbidity } \\
(\mathrm{n}=779)\end{array}$ & $\begin{array}{c}\text { Diabetes } \\
\text { only }(n=65)\end{array}$ & $\begin{array}{c}\text { Diabetes } \\
\text { with } \\
\text { comorbidities } \\
(\mathrm{n}=126)\end{array}$ & $P^{\dagger}$ value \\
\hline $\begin{array}{l}\text { WBC, } \\
\times 10^{9} \text { per L }\end{array}$ & $\begin{array}{l}5.42(4.18- \\
7.10)\end{array}$ & $\begin{array}{c}5.35(4.10- \\
6.95)\end{array}$ & $\begin{array}{l}5.93(4.49- \\
7.53)\end{array}$ & 0.003 & $\begin{array}{l}5.28(4.00- \\
6.77)\end{array}$ & $\begin{array}{l}6.11(4.27- \\
7.68)\end{array}$ & $\begin{array}{c}5.85 \\
(4.57-7.32)\end{array}$ & 0.001 \\
\hline $\begin{array}{l}\text { NEUT, } \times 10 \square \\
\text { per L }\end{array}$ & $\begin{array}{l}3.58(2.53- \\
5.12)\end{array}$ & $\begin{array}{c}3.45(2.46- \\
5.07)\end{array}$ & $\begin{array}{c}4.25(3.13- \\
5.37)\end{array}$ & $<0.001$ & $\begin{array}{l}3.29(2.33- \\
4.64)\end{array}$ & $\begin{array}{c}4.16(2.67- \\
5.40)\end{array}$ & $\begin{array}{c}4.37 \\
(3.20-5.29)\end{array}$ & $<0.001$ \\
\hline $\mathrm{LY}, \times 10 \square$ per & $\begin{array}{c}1.15(0.78- \\
1.59)\end{array}$ & $\begin{array}{c}1.17(0.80- \\
1.61)\end{array}$ & $\begin{array}{c}1.04(0.72- \\
1.43)\end{array}$ & 0.015 & $\begin{array}{l}1.25(0.86- \\
1.65)\end{array}$ & $\begin{array}{c}1.27(0.84- \\
1.73)\end{array}$ & $0.93(0.68-1.33)^{* *}$ & $<0.001$ \\
\hline NLR & $\begin{array}{l}2.95(1.97- \\
5.26)\end{array}$ & $\begin{array}{l}2.79(1.88- \\
4.93)\end{array}$ & $\begin{array}{l}3.84(2.45- \\
6.37)\end{array}$ & $<0.001$ & $\begin{array}{l}2.54(1.79- \\
4.36)\end{array}$ & $\begin{array}{l}3.15(2.08- \\
5.06)\end{array}$ & $4.29(2.62-7.30)^{*}$ & $<0.001$ \\
\hline $\mathrm{Hb}, \mathrm{g} / \mathrm{L}$ & $\begin{array}{c}130(118- \\
140)\end{array}$ & $\begin{array}{c}130(118- \\
140)\end{array}$ & $\begin{array}{c}120(117- \\
140)\end{array}$ & 0.195 & $131 \pm 16.3$ & $132 \pm 14.4$ & $125 \pm 17.6^{* *}$ & $<0.001$ \\
\hline $\begin{array}{l}\text { PLT, } \times 10 \square \text { per } \\
\text { L }\end{array}$ & $\begin{array}{l}\text { 196(150- } \\
251)\end{array}$ & $\begin{array}{l}\text { 196(151- } \\
251)\end{array}$ & $\begin{array}{c}196(147- \\
255)\end{array}$ & 0.714 & $\begin{array}{c}196(152- \\
242)\end{array}$ & 197(147-265) & $196(146-255)$ & 0.974 \\
\hline
\end{tabular}

$\mathrm{PCT}, \mathrm{ng} / \mathrm{mL}$

\begin{tabular}{lcccccccc}
\hline$<0.5$ & $981(94.4)$ & $838(94.4)$ & $143(94.7)$ & 0.869 & $585(97.3)$ & $53(100)$ & $90(91.8)$ & 0.006 \\
$\geq 0.5$ & $58(5.6)$ & $50(5.6)$ & $8(5.3)$ & & $16(2.7)$ & $0(0.0)$ & $8(8.2)$ &
\end{tabular}

CRP 10.9(1.7- $\quad 9.1\left(1.4-\quad 29.8\left(5.3-\quad<0.001 \quad 6.11\left(1.0-\quad 13.2(3.0-61.5) \quad 39.9(6.6-77.7)^{*}<0.001\right.\right.\right.$ $\begin{array}{llll}46.7) & 39.0) & 75.7) & <.001\end{array}$

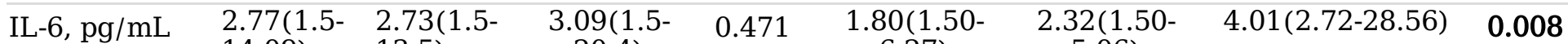

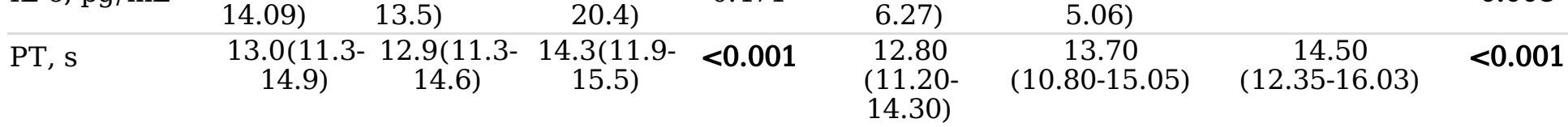

$<16$

830 (85.7) 712 (87.1) 118 (78.1) $\quad 0.004$

493 (87.7) $\quad 41$ (83.7)

75 (73.5) $\quad 0.001$

$\geq 16 \quad 138$ (14.3) 105 (12.9) 33 (21.9)

$\begin{array}{cccc}\text { D-dimer, mg/L } & 0.49(0.26- & 0.46(0.25- & 0.69(0.35- \\ 1.14) & 1.10) & 1.35)\end{array}$ 69 (12.3) $\quad 8$ (16.3)

27 (26.5)

$\leq 0.5 \quad 555(52.5) 497(55.0) \quad 58(37.9)$

$>0.5$ to $\leq 1.0 \quad 209(19.8) 163$ (18.0) 46 (30.1)

$>1.0 \quad 293$ (27.7) 244 (27.0) 49 (32.0)

ALB, g/L

$38.1 \pm 5.8 \quad 38.5 \pm 5.7 \quad 35.7 \pm 5.5$

$<0.001 \quad 0.38(0.23-$

$0.80)$

$0.46(0.26-$

$0.91)$

$<0.001 \quad 386(63.4) \quad 27(50.9)$

$0.83(0.46-1.94){ }^{* *}<0.001$

$100(16.4) \quad 18(34.0)$

$31(31.0)^{* *}$

$<0.001^{\mathrm{a}}$

ALT, U/L

23.1(14.2- 23.3(14.0- 23.0(16.039.0) 40.0) 34.0)

$123(20.2)$

$8(15.1)$

$28(28.0)$

$39.3 \pm 5.9^{* * *}$

$36.5 \pm 6.4$

$41(41.0)$

AST, U/L

28.8(22.0- 28.8(22.0- 29.0(20.040.4) 40.0) 41.0)

$\begin{array}{ll}<0.001 & 39.3 \pm 5.9^{* * *} \\ 0.844 & 22.0(13.8-\end{array}$

$21.0(16.3-$

$35.3 \pm 5.0$

$<0.001$ 39.0) 33.5)

ALP, U/L

58.0(46.0- 58.0(46.0- 55.0(43.5$\begin{array}{lll}73.0) & 73.0) & 74.0)\end{array}$

$0.583 \quad 27.0(21.0-$

38.0)

26.0(18.2-

36.5)

$\begin{array}{llll}58.0(45.0- & 53.0(38.0- & 58.0(45.0-77.0) & 0.086\end{array}$

72.0)

68.5)

TBIL, $\mathrm{mmol} / \mathrm{L} \quad 10.9(8.2-\quad 10.8(8.2-\quad 11.4(8.3-\quad 0.196$ 14.7) 14.5) 15.7)

$10.8(8.2-$

$11.4(9.5-14.8)$ 14.7)

$\begin{array}{lccc}\text { Potassium, } & 3.90(3.59- & 3.90(3.60- & 3.88(3.52 \\ & 4.20) & 4.20) & 4.21)\end{array}$

$3.94 \pm 0.51$

$3.94 \pm 0.49$

$11.3(8.0-15.8)$

0.429

0.325

$3.94 \pm 0.51$

$3.86 \pm 0.62$

0.279

$\mathrm{mmol} / \mathrm{L}$

Sodium,

139(137- 140(137- 138(136141)

141)

0.001

140 (138- 138 (136-141) $141)^{*}$

$\mathrm{mmol} / \mathrm{L}$

Chlorine ion, $104(102-105(102-\quad 103(100-$ $\mathrm{mmol} / \mathrm{L}$

Calcium,

$\mathrm{mmol} / \mathrm{L}$

107) 107) 106)

0.002

$104.2 \pm 5.3 \quad 103.1 \pm 4.5$

139(136-142)

0.002

Phosphorus,

2.11(2.00- 2.12(2.01- 2.09(1.95-

0.005

2.17)

$2.13 \pm 0.22$

$2.11 \pm 0.22$

2.21)

2.21)

$103.7 \pm 5.1$

0.218

Phosphorus,

1.03(0.89- 1.03(0.89- 1.01(0.73-

$0.359 \quad 1.04(0.90-$

1.03(0.92-

$1.00(0.85-1.19)$

0.300 


\begin{tabular}{|c|c|c|c|c|c|c|c|c|}
\hline $\mathrm{mmol} / \mathrm{L}$ & 1.19) & 1.19) & 1.18) & & 1.19) & 1.17) & & \\
\hline $\mathrm{BUN} \unrhd \mathrm{mmol} / \mathrm{L}$ & $\begin{array}{l}3.96(3.10- \\
5.25)\end{array}$ & $\begin{array}{c}3.90(3.10- \\
5.13)\end{array}$ & $\begin{array}{l}4.68(3.60- \\
\quad 6.20)\end{array}$ & $<0.001$ & $\begin{array}{l}3.70(2.96- \\
4.66)^{*}\end{array}$ & $\begin{array}{l}4.30(3.51- \\
5.07)\end{array}$ & $4.93(3.60-7.01)$ & $<0.001$ \\
\hline $\begin{array}{l}\text { Creatinine, } \\
\mu \mathrm{mol} / \mathrm{L}\end{array}$ & $\begin{array}{c}\text { 63.6(53.3- } \\
78.0)\end{array}$ & $\begin{array}{l}63.0(53.0- \\
77.4)\end{array}$ & $\begin{array}{l}66.3(54.0- \\
83.8)\end{array}$ & 0.088 & $\begin{array}{l}62.00 \\
(52.70- \\
73.00)\end{array}$ & $\begin{array}{c}60.00 \\
(52.00-76.60)\end{array}$ & $\begin{array}{c}67.75^{*} \\
(55.25-90.23)\end{array}$ & $<0.001$ \\
\hline $\mathrm{UA}, \mu \mathrm{mol} / \mathrm{L}$ & $\begin{array}{l}258(204- \\
336)\end{array}$ & $\begin{array}{l}\text { 257(205- } \\
336)\end{array}$ & $\begin{array}{l}258(193- \\
332)\end{array}$ & 0.725 & $\begin{array}{l}\text { 253(203- } \\
327)\end{array}$ & 248(194-306) & $264(191-352)$ & 0.499 \\
\hline $\mathrm{CK}, \mathrm{U} / \mathrm{L}$ & $\begin{array}{l}65.0(43.0- \\
110)\end{array}$ & $\begin{array}{l}64.5(44.0- \\
109)\end{array}$ & $\begin{array}{c}66.5(40.3- \\
118)\end{array}$ & 0.830 & $\begin{array}{l}62.0(44.0- \\
98.0)\end{array}$ & $58.5(36.8-108)$ & $70.0(43.8-122)$ & 0.233 \\
\hline $\mathrm{LDH}, \mathrm{U} / \mathrm{L}$ & $\begin{array}{l}205(162- \\
272)\end{array}$ & $\begin{array}{l}201(160- \\
261)\end{array}$ & $\begin{array}{l}229(180- \\
341)\end{array}$ & $<0.001$ & $\begin{array}{c}\text { 186(155- } \\
239)\end{array}$ & 198(164-282) & $251(195-362){ }^{*}$ & $<0.001$ \\
\hline $\begin{array}{l}\text { Hs-cTnI>ULN, } \\
\mathrm{pg} / \mathrm{mL}\end{array}$ & $130(22.1)$ & $117(23.4)$ & $13(14.90)$ & 0.080 & $71(23.5)$ & $3(12.5)$ & $6(9.5)$ & 0.027 \\
\hline $\mathrm{TG}, \mathrm{mmol} / \mathrm{L}$ & $\begin{array}{c}1.22(0.92- \\
1.78)\end{array}$ & $\begin{array}{c}1.20(0.89- \\
1.77)\end{array}$ & $\begin{array}{c}1.39(1.04- \\
1.83)\end{array}$ & 0.002 & $\begin{array}{c}1.18(0.86- \\
1.77)\end{array}$ & $\begin{array}{c}1.50(1.05- \\
2.08)\end{array}$ & $1.36(1.03-1.79)^{*}$ & 0.004 \\
\hline $\mathrm{TCH}, \mathrm{mmol} / \mathrm{L}$ & $\begin{array}{l}4.00(3.40- \\
4.80)\end{array}$ & $\begin{array}{l}4.01(3.42- \\
4.80)\end{array}$ & $\begin{array}{l}4.00(3.22- \\
\quad 4.78)\end{array}$ & 0.180 & $4.25 \pm 1.09$ & $4.34 \pm 1.07$ & $3.88 \pm 1.08^{*}$ & 0.004 \\
\hline $\begin{array}{l}\text { LDL-C, } \\
\mathrm{mmol} / \mathrm{L}\end{array}$ & $\begin{array}{l}2.50(3.00- \\
3.12)\end{array}$ & $\begin{array}{l}2.51(2.02- \\
3.10)\end{array}$ & $\begin{array}{l}2.48(1.87- \\
3.15)\end{array}$ & 0.368 & $2.65 \pm 0.89$ & $2.76 \pm 0.91$ & $2.41 \pm 0.87^{*}$ & 0.020 \\
\hline $\begin{array}{l}\text { HDL-C, } \\
\mathrm{mmol} / \mathrm{L}\end{array}$ & $\begin{array}{c}1.01(0.82- \\
1.21)\end{array}$ & $\begin{array}{c}1.03(0.84- \\
1.24)\end{array}$ & $\begin{array}{l}0.91(0.76- \\
1.08)\end{array}$ & $<0.001$ & $1.11 \pm 0.42^{*}$ & $0.97 \pm 0.26$ & $0.92 \pm 0.27$ & $<0.001$ \\
\hline FPG, mmol/L & $\begin{array}{l}5.80(5.00- \\
7.46)\end{array}$ & $\begin{array}{l}5.57(4.92- \\
\quad 6.89)\end{array}$ & $\begin{array}{l}9.10(6.50- \\
11.63)\end{array}$ & $<0.001$ & $\begin{array}{c}5.37(4.83- \\
6.50)^{* * *}\end{array}$ & $\begin{array}{c}9.40(6.48- \\
11.59)\end{array}$ & $8.80(6.50-12.03)$ & $<0.001$ \\
\hline $3.9-6.9$ & $693(69.0)$ & $650(76.7)$ & $43(27.6)$ & $<0.001$ & $475 \underset{* * *}{(80.2)}$ & $17(29.8))$ & $26(26.3)$ & $<0.001^{\mathrm{a}}$ \\
\hline $7.0-11.1$ & $241(24.0)$ & $179(21.1)$ & $62(39.7)$ & & $108(18.2)$ & $22(38.6)$ & $40(40.4)$ & \\
\hline$\geq 11.1$ & $70(7.0)$ & $19(2.2)$ & $51(32.7)$ & & $9(1.5)$ & $18(31.6)$ & $33(33.3)$ & \\
\hline $\mathrm{HbA} 1 \mathrm{C}$ & $\begin{array}{c}6.20(5.55- \\
7.30)\end{array}$ & $\begin{array}{c}5.90(5.40- \\
6.30)\end{array}$ & $\begin{array}{l}\text { 7.87(6.27- } \\
9.03)\end{array}$ & $<0.001$ & $\begin{array}{c}5.9(5.44- \\
6.20)^{* *}\end{array}$ & $\begin{array}{l}7.60(5.64- \\
8.98)\end{array}$ & $7.89(6.75-9.21)$ & $<0.001$ \\
\hline
\end{tabular}

Data are expressed as $\mathrm{n}(\%)$, mean \pm SD or median (IQR). P values were calculated by T Test, Mann-Whitney U test, $\mathrm{x}^{2}$ test, Fisher's exact test, One-Way ANOVA or Kruskal-Wallis H test as appropriate. ${ }^{\mathrm{a}}$ Mann-Whitney U tes 1 comparing all subcategories. \#Comparing groups of diabetic and non-diabetic patients; †Comparing groups of non-comorbidity, only diabetes and diabetes with comorbidities. Compared with diabetes only group ${ }^{*} \mathrm{P}<0.05, * * \mathrm{P}<0.05, * * * \mathrm{P}<0.001$. WBC, white blood cell; NEUT, neutrophil ; LY, lymphocyte ; NLR, neutrophi. lymphocyte ratio; $\mathrm{Hb}$, hemoglobin; PLT, platelet; PCT, procalcitonin; CRP, C reactive protein; PT, prothrombir time ; ALB, albumin; ALT, alanine aminotransferase; AST, aspartate aminotransferase ; ALP, alkalin€ phosphatase ; TBIL, total bilirubin ; BUN, urea nitrogen; UA, uric acid ; CK, creatine kinase ; LDH, lactat€ dehydrogenase ; Hs-cTnI, hypersensitive troponin I ; TG, triglyceride; TCH, total cholesterol; LDL-C, low density lipoprotein cholesterol; HDL-C, high density lipoprotein cholesterol; FPG, fasting plasma glucose. HbA1C, glycosylated hemoglobin.

Table 3. Treatments and outcomes of 1331 COVID-19 patients divided into different groups 


\begin{tabular}{|c|c|c|c|c|c|}
\hline $\begin{array}{c}\text { Total } \\
(n=1331)\end{array}$ & $\begin{array}{c}\text { Non- } \\
\text { diabetes } \\
(\mathrm{n}=1140)\end{array}$ & $\begin{array}{l}\text { Diabetes } \\
(\mathrm{n}=191)\end{array} P^{\#}$ val & $\begin{array}{c}\text { Non- } \\
\text { comorbidity } \\
(n=779)\end{array}$ & $\begin{array}{c}\text { Diabetes } \\
\text { only } \\
(\mathrm{n}=65)\end{array}$ & $\begin{array}{c}\text { Diabetes } \\
\text { with } \\
\text { comorbidities }\end{array}$ \\
\hline
\end{tabular}

$(n=126)$

\section{Treatments}

Antiviral therapy

1227(92.2) 1057(92.7) 170(89.0) 0.077

725(93.1) 62(95.4)

$108(85.7)$

0.010

Antibiotic therapy

$\begin{array}{llll}1142(85.8) & 982(86.1) & 160(83.8) & 0.385\end{array}$

665(85.4) 57(87.7) 103(81.7)

0.472

Systemic glucocorticoid

$\begin{array}{llll}533(40.0) & 458(40.2) & 75(39.3) & 0.813\end{array}$

292(37.5) 23(35.4)

$52(41.3)$

0.657

Intravenous

$\begin{array}{llll}403(30.3) & 342(30.0) & 61(31.9) & 0.590\end{array}$

210(27.0) 18(27.7)

$43(34.1)$

0.250

immunoglobulin

Renal replacement

$$
2(0.2)
$$

$1(0.1)$

$1(0.5)$

0.267

$0(0.0)$

$0(0.0)$

$1(0.8)$

0.197

therapy

\section{Oxygen support}

Oxygenation

786(59.1) $\quad 672(58.9) \quad 114(59.7) \quad 0.848$

426(54.7) 38(58.5)

76(60.3)

0.446

Mechanical ventilation

$\begin{array}{llll}154(11.6) & 124(10.9) & 30(15.7) & 0.053\end{array}$

$68(8.7)$

$7(10.8)$

23(18.3)

0.004

\section{Illness severity}

Severe

313 (23.5) 247 (21.7) 66 (34.6) $\quad 0.001$

123 (15.8) 14 (21.5)

$52(41.3)^{*} \quad<0.001$

\section{Complications}

\begin{tabular}{|c|c|c|c|c|c|c|c|c|}
\hline ARDS & $86(6.5)$ & $65(5.7)$ & $21(11.0)$ & 0.006 & $26(3.3)$ & $2(3.1)$ & $19(15.1)$ & $<0.001$ \\
\hline $\mathrm{ACI}$ & $148(11.1)$ & $132(11.6)$ & $16(8.4)$ & 0.193 & $77(9.9)$ & $3(4.6)$ & $12(9.5)$ & 0.379 \\
\hline AKI & $18(1.4)$ & $14(1.2)$ & $4(2.1)$ & 0.535 & $6(0.8)$ & $1(1.5)$ & $3(2.4)$ & 0.122 \\
\hline Secondary infection & $161(12.1)$ & $139(12.2)$ & $22(11.5)$ & 0.791 & $76(9.8)$ & $4(6.2)$ & $18(14.3)$ & 0.162 \\
\hline Shock & $25(1.9)$ & $23(2.0)$ & $2(1.0)$ & 0.531 & $9(1.2)$ & $0(0.0)$ & $2(1.6)^{*}$ & 0.706 \\
\hline $\begin{array}{l}\text { Hypoproteinemia } \\
<30 \mathrm{~g} / \mathrm{l}\end{array}$ & $99(7.7)$ & $71(6.5)$ & $28(15.0)$ & $<0.001$ & $38(5.0)^{* * *}$ & $11(16.9)$ & $17(13.9)$ & $<0.001$ \\
\hline $\begin{array}{l}\text { Length of hospital stay, } \\
\text { d }\end{array}$ & $\begin{array}{l}17.0 \\
(10.0- \\
24.0)\end{array}$ & $\begin{array}{l}17.0 \\
(10.0- \\
24.0)\end{array}$ & $\begin{array}{l}16.0 \\
(10.0- \\
25.0)\end{array}$ & 0.655 & $\begin{array}{c}17.0 \\
(11.0-24.0)\end{array}$ & $\begin{array}{l}19.0 \\
(11.5- \\
27.0)\end{array}$ & $\begin{array}{c}16.0 \\
(8.0-22.5)\end{array}$ & 0.109 \\
\hline ICU admission & $125(9.4)$ & $103(9.0)$ & $22(11.5)$ & 0.276 & $57(7.3)$ & $5(7.7)$ & $17(13.5)$ & 0.062 \\
\hline $\begin{array}{l}\text { Duration from } \\
\text { admission to ICU, d }\end{array}$ & $\begin{array}{l}4.00 \\
(1.00- \\
7.50)\end{array}$ & $\begin{array}{l}5.00 \\
(1.00- \\
8.00)\end{array}$ & $\begin{array}{l}3.50 \\
(1.75- \\
5.25)\end{array}$ & 0.383 & $\begin{array}{c}4.50 \\
(1.00-8.00)\end{array}$ & $\begin{array}{l}5.00 \\
(1.50- \\
6.00)\end{array}$ & $\begin{array}{c}3 \\
(1.50-4.50)\end{array}$ & 0.733 \\
\hline \multicolumn{9}{|l|}{ Prognosis } \\
\hline Death, No & $108(8.1)$ & $82(7.2)$ & $26(13.6)$ & 0.003 & $26(3.3)$ & $3(4.6)$ & $23(18.3)$ & $<0.001$ \\
\hline
\end{tabular}

Data are expressed as $\mathrm{n}(\%)$, mean \pm SD or median (IQR). $P$ values were calculated by T Test, Mann-Whitney U test, $\mathrm{x}^{2}$ test, Fisher's exact test, One-Way ANOVA or Kruskal-Wallis $\mathrm{H}$ test as appropriate. ${ }^{*}$ Comparing groups of diabetic and non-diabetic patients; †Comparing groups of non-comorbidity, only diabetes and diabetes with comorbidities. Compared with diabetes only group: $* P<0.05, * * P<0.05, * * * P<0.001$. ARDS, acute respiratory distress syndrome; ACI, acute cardiac injury; AKI, acute kidney injury.

\section{Table 4. Laboratory results of diabetic survivors and non-survivors with COVID-19}




\begin{tabular}{|c|c|c|c|c|}
\hline & $\begin{array}{c}\text { Total } \\
(n=191)\end{array}$ & $\begin{array}{c}\text { Survivors } \\
(\mathrm{n}=165)\end{array}$ & $\begin{array}{l}\text { Non-survivors } \\
(n=26)\end{array}$ & $P$ value \\
\hline $\mathrm{WBC}, \times 10^{9}$ per $\mathrm{L}$ & $5.94(4.49-7.53)$ & $5.91(4.42-7.29)$ & $7.26(5.19-13.07)$ & 0.016 \\
\hline NEUT, $\times 10 \square$ per L & $4.25(3.13-5.37)$ & $4.09(3.01-5.13)$ & $6.22(3.69-11.33)-$ & $<0.001$ \\
\hline $\mathrm{LY}, \times 10 \square$ per $\mathrm{L}$ & $1.04(0.72-1.43)$ & $1.08(0.78-1.48)$ & $0.65(0.56-1.07)$ & $<0.001$ \\
\hline NLR & $3.85(2.45-6.37)$ & $3.50(2.33-5.53)$ & $10.43(5.78-16.84)$ & $<0.001$ \\
\hline $\mathrm{Hb}, \mathrm{g} / \mathrm{L}$ & $127.3 \pm 16.9$ & $126.8 \pm 16.7$ & $131.6 \pm 18.3$ & 0.314 \\
\hline $\mathrm{PLT}, \times 10 \square$ per $\mathrm{L}$ & $196(147-255)$ & $201(152-201)$ & $155(110-230)$ & 0.033 \\
\hline \multicolumn{5}{|l|}{$\mathrm{PCT}, \mathrm{ng} / \mathrm{mL}$} \\
\hline$<0.5$ & $143(94.7)$ & 132(98.5) & $11(64.7)$ & $<0.001$ \\
\hline$\geq 0.5$ & $8(5.3)$ & $2(1.5)$ & $6(35.3)$ & \\
\hline CRP & $29.8(5.5-75.9)$ & $25.4(4.4-63.0)$ & $115.3(66.1-170.6)$ & $<0.001$ \\
\hline IL-6, pg/mL & $3.31(1.64-17.49)$ & $3.09(1.50-5.25)$ & $83.47(35.75-243.60)$ & $<0.001$ \\
\hline PT, s & $14.30(11.90-15.50)$ & $14.00(11.60-15.40)$ & $16.20(13.52-18.92)$ & 0.002 \\
\hline$<16$ & $116(76.8)$ & $110(81.5)$ & $6(37.5)$ & $<0.001$ \\
\hline$\geq 16$ & $35(23.2)$ & $25(18.5)$ & $10(62.5)$ & \\
\hline D-dimer, mg/L & $0.69(0.35-1.35)$ & $0.62(0.62-1.09)$ & $5.40(1.50-21.00)$ & $<0.001$ \\
\hline$\leq 0.5$ & $58(37.9)$ & $57(41.9)$ & $1(5.9)$ & $<0.001^{\mathrm{a}}$ \\
\hline$>0.5$ to $\leq 1.0$ & $46(30.1)$ & $43(31.6)$ & $3(17.6)$ & \\
\hline$>1.0$ & $49(32.0)$ & $36(26.5)$ & $13(76.5)$ & \\
\hline $\mathrm{ALB}, \mathrm{g} / \mathrm{L}$ & $35.7 \pm 5.5$ & $36.0 \pm 30.5$ & $33.5 \pm 23.4$ & 0.031 \\
\hline $\mathrm{ALT}, \mathrm{U} / \mathrm{L}$ & $23.0(16.0-34.0)$ & $21.3(15.3-32.3)$ & $31.0(20.9-46.6)$ & 0.008 \\
\hline $\mathrm{AST}, \mathrm{U} / \mathrm{L}$ & $29.0(20.0-41.0)$ & $27.0(19.0-38.7)$ & $43.0(31.0-60.5)$ & $<0.001$ \\
\hline $\mathrm{ALP}, \mathrm{U} / \mathrm{L}$ & $55.0(43.5-74.0)$ & $55.0(41.5-73.0)$ & $57.0(49.5-89.5)$ & 0.241 \\
\hline TBIL, mmol/L & $11.3(8.3-15.7)$ & $11.4(9.0-15.1)$ & $11.2(7.6-28.0)$ & 0.642 \\
\hline Potassium, mmol/L & $3.88(3.52-4.21)$ & $3.90(3.54-4.21)$ & $3.65(3.37-4.30)$ & 0.381 \\
\hline Sodium, mmol/L & $138.4 \pm 4.3$ & $138.2 \pm 3.9$ & $139.3 \pm 6.4$ & 0.418 \\
\hline Chlorine ion, $\mathrm{mmol} / \mathrm{L}$ & $103.5 \pm 4.9$ & $103.2 \pm 4.7$ & $105.3 \pm 6.0$ & 0.052 \\
\hline
\end{tabular}




\begin{tabular}{|c|c|c|c|c|}
\hline Calcium, mmol/L & $2.09(1.95-2.17)$ & $2.10(1.95-2.20)$ & $2.00(1.89-2.11)$ & 0.042 \\
\hline Phosphorus, mmol/L & $1.01(0.86-1.18)$ & $1.02(0.87-1.19)$ & $0.93(0.76-1.18)$ & 0.268 \\
\hline $\mathrm{BUN} \square \mathrm{mmol} / \mathrm{L}$ & $4.70(3.60-6.22)$ & $4.5(3.59-5.82)$ & $6.51(4.92-17.45)$ & $<0.001$ \\
\hline Creatinine, $\mu \mathrm{mol} / \mathrm{L}$ & $66.3(54.0-83.8)$ & $64.0(44.6-81.0)$ & $73.0(64.0-129.6)$ & 0.006 \\
\hline $\mathrm{UA}, \mu \mathrm{mol} / \mathrm{L}$ & $258(193-332)$ & $258(147-321)$ & $293(179-428)$ & 0.286 \\
\hline $\mathrm{CK}, \mathrm{U} / \mathrm{L}$ & 66.5(40.3-117.8) & $61.0(36.5-111.0)$ & $85.0(71.0-364.0)$ & 0.002 \\
\hline $\mathrm{LDH}, \mathrm{U} / \mathrm{L}$ & $229(180-341)$ & $216(172-219)$ & $522(420-611)$ & $<0.001$ \\
\hline Hs-cTnI>ULN, pg/mL & $10 / 88(11.4)$ & $8 / 72(11.1)$ & $2 / 16(12.5)$ & 1.000 \\
\hline $\mathrm{TG}, \mathrm{mmol} / \mathrm{L}$ & $1.39(1.04-1.83)$ & $1.41(1.05-1.98)$ & $1.31(0.99-1.57)$ & 0.398 \\
\hline $\mathrm{TCH}, \mathrm{mmol} / \mathrm{L}$ & $4.04 \pm 1.10$ & $4.12 \pm 1.06$ & $3.39 \pm 1.16$ & 0.009 \\
\hline LDL-C, mmol/L & $2.54 \pm 0.90$ & $2.59 \pm 0.88$ & $2.10 \pm 0.93$ & 0.036 \\
\hline HDL-C, mmol/L & $0.94 \pm 0.26$ & $0.94 \pm 0.26$ & $0.89 \pm 0.33$ & 0.450 \\
\hline FPG, mmol/L & $9.10(6.50-11.72)$ & $8.70(6.50-11.36)$ & $12.00(9.40-16.81)$ & 0.011 \\
\hline $3.9-6.9$ & $43(27.7)$ & $40(28.6)$ & $3(20.0)$ & $0.069^{\mathrm{a}}$ \\
\hline $7.0-11.1$ & $61(39.4)$ & $58(41.4)$ & $3(20.0)$ & \\
\hline$\geq 11.1$ & $51(32.9)$ & $42(30.0)$ & $9(60.0)$ & \\
\hline $\mathrm{HbA1C}$ & $7.77 \pm 1.97$ & $7.61 \pm 1.90$ & $9.53 \pm 2.02$ & 0.021 \\
\hline
\end{tabular}

Data are expressed as $\mathrm{n}(\%)$, mean \pm SD or median(IQR). $P$ values were calculated by $\mathrm{T}$ test, Mann-Whitney $\mathrm{U}$ test, $\mathrm{x}^{2}$ test, or Fisher's exact test, as appropriate. a Mann-Whitney $\mathrm{U}$ test comparing all subcategories. $P$, comparing groups of diabetic survivors and non-survivors. WBC, white blood cell; NEUT, neutrophil ; LY, lymphocyte ; NLR, neutrophil lymphocyte ratio; Hb, hemoglobin; PLT, platelet; PCT, procalcitonin; CRP, C reactive protein; PT, prothrombin time ; ALB, albumin; ALT, alanine aminotransferase; AST, aspartate aminotransferase ; ALP, alkaline phosphatase ; TBIL, total bilirubin ; BUN, urea nitrogen ; UA, uric acid ; $\mathrm{CK}$, creatine kinase ; LDH, lactate dehydrogenase ; Hs-CTnI, hypersensitive troponin I ; TG, triglyceride; TCH, total cholesterol; LDL-C, low density lipoprotein cholesterol; HDL-C, high density lipoprotein cholesterol; FPG, fasting plasma glucose; HbA1C, glycosylated Hemoglobin.

Table 5. Treatments and outcomes of diabetic survivors and non-survivors with COVID-19 


\begin{tabular}{|c|c|c|c|c|}
\hline \multirow[b]{2}{*}{ Treatments } & \multirow[t]{2}{*}{$\begin{array}{c}\text { Total } \\
(n=191)\end{array}$} & \multirow[t]{2}{*}{$\begin{array}{l}\text { Survivors } \\
(\mathrm{n}=165)\end{array}$} & \multicolumn{2}{|c|}{$\begin{array}{l}\text { Non-survivors } P \text { value } \\
\quad(\mathrm{n}=26)\end{array}$} \\
\hline & & & & \\
\hline Antiviral therapy & $170(89.0)$ & $149(90.3)$ & $21(80.8)$ & 0.268 \\
\hline Antibiotic therapy & $160(83.8)$ & $139(84.2)$ & $21(80.8)$ & 0.873 \\
\hline Systemic glucocorticoids & $74(38.7)$ & $55(33.3)$ & $19(73.1)$ & $<0.001$ \\
\hline Intravenous immunoglobulin & $60(31.4)$ & $50(30.3)$ & $10(38.5)$ & 0.405 \\
\hline Renal replacement therapy & $1(0.5)$ & $0(0.0)$ & $1(3.8)$ & 0.136 \\
\hline Insulin & $88(46.1)$ & $75(45.5)$ & $13(50.0)$ & 0.666 \\
\hline Metformin & $54(28.3)$ & $51(30.9)$ & $3(11.5)$ & 0.041 \\
\hline Sulfonylurea & $37(19.4)$ & $36(21.8)$ & $1(3.8)$ & 0.031 \\
\hline DPP-4 inhibitor & $11(5.8)$ & $10(6.1)$ & $1(3.8)$ & 1.000 \\
\hline Acarbose & $77(40.3)$ & $75(45.5)$ & $2(7.7)$ & $<0.001$ \\
\hline Thiazolidinedione & $7(3.7)$ & $7(4.2)$ & $0(0.0)$ & 0.596 \\
\hline \multicolumn{5}{|l|}{ Oxygen support } \\
\hline Oxygenation & $115(60.2)$ & $95(57.6)$ & $20(76.9)$ & 0.061 \\
\hline Mechanical ventilation & $35(18.3)$ & $15(9.1)$ & $20(76.9)$ & $<0.001$ \\
\hline \multicolumn{5}{|l|}{ Illness severity } \\
\hline Severe & $63(33.0)$ & $37(33.7)$ & $26(100)$ & $<0.001$ \\
\hline \multicolumn{5}{|l|}{ Complications } \\
\hline ARDS & $21(11.0)$ & $5(3.0)$ & $16(61.5)$ & $<0.001$ \\
\hline ACI & $16(8.4)$ & $9(5.5)$ & $7(26.9)$ & 0.001 \\
\hline AKI & $3(1.6)$ & $1(0.6)$ & $2(7.7)$ & 0.049 \\
\hline Secondary infection & $22(11.5)$ & $10(6.1)$ & $12(46.2)$ & $<0.001$ \\
\hline Shock & $3(1.6)$ & $0(0.0)$ & $3(11.5)$ & 0.002 \\
\hline Hypoproteinemia $<30 \mathrm{~g} / \mathrm{l}$ & $28(14.7)$ & $22(13.3)$ & $6(23.1)$ & 0.314 \\
\hline
\end{tabular}




\begin{tabular}{lcccc} 
Coagulopathy & $36(18.8)$ & $26(15.8)$ & $10(38.5)$ & 0.013 \\
\hline Length of hospital stay, days & $16.0(10.0-25.0)$ & $18.0(11.5-26.0)$ & $7.0(3.0-11.0)$ & $<0.001$ \\
\hline ICU admission & $22(11.5)$ & $11(6.7)$ & $11(42.3)$ & $<0.001$ \\
\hline Duration from admission to ICU, d & $4.00 \pm 3.51$ & $3.91 \pm 3.11$ & $4.09 \pm 4.01$ & 0.907
\end{tabular}

Data are expressed as n (\%), mean \pm SD or median(IQR). $P$ values were calculated by T test, Mann-Whitney U test x2 test, or Fisher's exact test, as appropriate. Comparing groups of diabetic survivors and non-survivors. ARDS acute respiratory distress syndrome; ACI, acute cardiac injury; AKI, acute kidney injury

Table 6. Laboratory results of diabetic COVID-19 patients using metformin or acarbose and matched non-metformin or non-acarbose inhibitor user 


\begin{tabular}{|c|c|c|c|c|}
\hline & $\begin{array}{c}\text { Metformin } \\
(n=50)\end{array}$ & $\begin{array}{l}\text { Matched non-Metformin } \\
\qquad(\mathrm{n}=50)\end{array}$ & $\begin{array}{c}\text { Acarbose } \\
(\mathrm{n}=46)\end{array}$ & $\begin{array}{c}\text { Matched non-acarbose } \\
(\mathrm{n}=46)\end{array}$ \\
\hline$\overline{W B C}, \times 10^{9}$ per $L$ & $6.33 \pm 2.25$ & $6.27 \pm 2.62$ & $4.83(4.04,6.68)$ & $5.91(4.42,9.35){ }^{\#}$ \\
\hline NEUT, $\times 10 \square$ per L & $4.20(3.02-5.18)$ & $4.17(3.21-5.87)$ & $3.50(2.48-4.74)$ & $4.60(3.14-8.13)$ \\
\hline $\mathrm{LY}, \times 10 \square$ per $\mathrm{L}$ & $1.20(0.69-1.74)$ & $1.14(0.82-1.50)$ & $1.19 \pm 0.55$ & $1.04 \pm 0.53$ \\
\hline NLR & $3.69(2.11-6.05)$ & $3.74(2.47-5.55)$ & $3.25(2.05-4.41)$ & $4.88(2.50-12.32)$ \#\# \\
\hline $\mathrm{Hb}, \mathrm{g} / \mathrm{L}$ & $126.0 \pm 15.7$ & $126.5 \pm 14.9$ & $126.0 \pm 16.9$ & $129.3 \pm 17.3$ \\
\hline PLT, $\times 10 \square$ per $L$ & $229.5 \pm 93.5$ & $208.5 \pm 103.8$ & $233.0 \pm 93.2$ & $214.2 \pm 99.7$ \\
\hline \multicolumn{5}{|l|}{$\mathrm{PCT}, \mathrm{ng} / \mathrm{mL}$} \\
\hline$<0.5$ & $43(100.0)$ & $34(91.9)$ & $37(100.0)$ & $34(87.2)$ \\
\hline$\geq 0.5$ & $0(0.0)$ & $3(8.1)$ & $0(0.0)$ & $5(12.8)$ \\
\hline CRP & $50.7(5.0-78.0)$ & $46.5(6.3-106.8)$ & $26.2(3.7-52.2)$ & $63.8(10.8-83.4))^{\#}$ \\
\hline IL-6, pg/mL & $2.07(1.50-4.90)$ & $3.20(1.68-67.28)$ & $2.58(1.50-5.06)$ & 19.88(1.95-67.28) \\
\hline $\mathrm{PT}, \mathrm{s}$ & $13.5 \pm 2.7$ & $14.2 \pm 2.2$ & $14.1 \pm 2.6$ & $14.2 \pm 3.2$ \\
\hline$<16$ & $37(86.0)$ & $31(79.5)$ & $30(78.9)$ & $27(73.0)$ \\
\hline$\geq 16$ & $6(14.0)$ & $8(20.5)$ & $8(21.1)$ & $10(27.0)$ \\
\hline D-dimer, mg/L & $0.45(0.26-1.19)$ & $0.83(0.33-1.60)$ & $0.59(0.33-0.98)$ & $0.96(0.39-5.40)$ \\
\hline$\leq 0.5$ & $22(52.4)$ & $13(33.3)$ & $18(42.9)$ & $12(33.3)$ \\
\hline$>0.5$ to $\leq 1.0$ & $6(14.3)$ & $11(28.2)$ & $15(35.7)$ & $7(19.4)$ \\
\hline$>1.0$ & $14(33.3)$ & $15(38.5)$ & $9(21.4)$ & $17(47.2)$ \\
\hline $\mathrm{ALB}, \mathrm{g} / \mathrm{L}$ & $35.7 \pm 5.9$ & $35.8 \pm 5.5$ & $35.7 \pm 6.5$ & $35.1 \pm 4.8$ \\
\hline $\mathrm{ALT}, \mathrm{U} / \mathrm{L}$ & $20.0(13.5-27.5)$ & $22.0(17.0-36.0)$ & $20.0(14.0-31.0)$ & $\begin{array}{c}23.00 \\
(14.00-33.25)\end{array}$ \\
\hline AST, U/L & $25.5(18.5-33.7)$ & $29.0(20.0-42.0)$ & $23.0(17.5-36.4)$ & $31.0(21.5-39.6)$ \\
\hline $\mathrm{ALP}, \mathrm{U} / \mathrm{L}$ & $51.0(37.0-71.0)$ & $54.0(44.0-68.0)$ & $59.5 \pm 24.6$ & $61.5 \pm 25.5$ \\
\hline TBIL, mmol/L & $12.2 \pm 5.4$ & $13.4 \pm 16.2$ & $11.5 \pm 4.8$ & $13.5 \pm 5.4$ \\
\hline Potassium, mmol/L & $3.81 \pm 0.46$ & $3.77 \pm 0.54$ & $3.90 \pm 0.50$ & $3.82 \pm 0.63$ \\
\hline Sodium, mmol/L & $137.9 \pm 3.9$ & $138.2 \pm 4.1$ & 138. $5 \pm 3.8$ & $138.1 \pm 4.7$ \\
\hline Chlorine ion, $\mathrm{mmol} / \mathrm{L}$ & $103.3 \pm 4.5$ & $103.4 \pm 5.0$ & $103.2 \pm 4.6$ & $103.7 \pm 5.3$ \\
\hline Calcium, mmol/L & $2.14 \pm 0.22$ & $2.05 \pm 0.18^{*}$ & $2.12 \pm 0.22$ & $2.08 \pm 0.19$ \\
\hline Phosphorus, mmol/L & $1.02(0.83-1.21)$ & $0.99(0.87-1.17)$ & $1.07(0.88-1.21)$ & $1.00(0.77-1.21)$ \\
\hline BUN口mmol/L & $4.40(3.67-4.84)$ & $5.20(3.50-5.75)$ & $4.16(3.60-5.18)$ & $5.04(3.80-6.64)$ \\
\hline Creatinine, $\mu \mathrm{mol} / \mathrm{L}$ & $54.0(49.0-73.7)$ & $60.0(52.5-90.3)$ & $59.5(48.8-74.5)$ & $68.0(55.0-89.3)$ \\
\hline $\mathrm{UA}, \mu \mathrm{mol} / \mathrm{L}$ & $266.5 \pm 96.6$ & $260.9 \pm 98.7$ & $229(168-263)$ & $258(179-324)$ \\
\hline $\mathrm{CK}, \mathrm{U} / \mathrm{L}$ & $64.0(49.0-84.0)$ & $82.0(39.0-135.3)$ & $53.5(35.5-73.8)$ & $71.0(40.0-114.0)$ \\
\hline $\mathrm{LDH}, \mathrm{U} / \mathrm{L}$ & $237 \pm 115$ & $304 \pm 162 *$ & $229(185-263)$ & $267(181-446)$ \\
\hline Hs-cTnI >ULN , pg/mL & $0 / 24(0.0)$ & $3 / 15(20.0)$ & $1 / 21(4.8)$ & $2 / 26(7.7)$ \\
\hline $\mathrm{TG}, \mathrm{mmol} / \mathrm{L}$ & $1.55(1.15-1.82)$ & $1.32(1.08-3.40)$ & $1.36(1.05-1.83)$ & $1.15(0.94-1.61)$ \\
\hline $\mathrm{TCH}, \mathrm{mmol} / \mathrm{L}$ & $3.91 \pm 0.87$ & $3.80 \pm 0.92$ & $4.40 \pm 1.14$ & $4.04 \pm 0.96$ \\
\hline $\mathrm{LDL}-\mathrm{C}, \mathrm{mmol} / \mathrm{L}$ & $2.40 \pm 0.73$ & $2.43 \pm 0.78$ & $2.84 \pm 0.87$ & $2.57 \pm 0.83$ \\
\hline
\end{tabular}




\begin{tabular}{lcccc} 
HDL-C, mmol/L & $0.93 \pm 0.22$ & $0.88 \pm 0.28$ & $0.98 \pm 0.27$ & $0.93 \pm 0.23$ \\
\hline FPG, mmol/L & $\mathbf{1 0 . 5 7} \pm \mathbf{4 . 9 2}$ & $\mathbf{8 . 3 2} \pm \mathbf{2 . 4 7 * *}$ & $9.92 \pm 4.90$ & $10.00 \pm 4.26$ \\
\hline $3.9-6.9$ & $11(44.0)$ & $13(38.2)$ & $12(30.8)$ & $8(22.2)$ \\
\hline $7.0-11.1$ & $13(52.0)$ & $21(61.8)$ & $13(33.3)$ & $16(44.4)$ \\
$\geq 11.1$ & $1(4.0)$ & $0(0.0)$ & $14(35.9)$ & $12(33.3)$ \\
\hline HbA1C & $7.96 \pm 1.85$ & $6.71 \pm 1.94$ & $7.85 \pm 1.78$ & $8.25 \pm 2.04$ \\
\hline
\end{tabular}

Data are expressed as $\mathrm{n}(\%)$, mean \pm SD or median (IQR). Comparison of metformin users and non-users: ${ }^{*} P<0.05, \quad * * P<0.01, \quad * * * P<0.001$. Comparison of acarbose users and non-users:: ${ }^{*} P<0.05, \quad{ }^{\# \#} P<0.01$, \#\#\# $P<0.05$. WBC, white blood cell; NEUT, neutrophil ; LY, lymphocyte ; NLR, neutrophil lymphocyte ratio; $\mathrm{Hb}$, hemoglobin; PLT, platelet; PCT, procalcitonin; CRP, C reactive protein; PT, prothrombin time ; ALB, albumin; ALT, alanine aminotransferase; AST, aspartate aminotransferase ; ALP, alkaline phosphatase ; TBIL, total bilirubin ; BUN, urea nitrogen ; UA, uric acid ; CK, creatine kinase ; LDH, lactate dehydrogenase ; HscTnI, hypersensitive troponin I ; TG, triglyceride; TCH, total cholesterol; LDL-C, low density lipoprotein cholesterol; HDL-C, high density lipoprotein cholesterol; FPG, fasting plasma glucose; HbA1C, glycosylated hemoglobin.

Table 7. Treatments and outcomes of diabetic COVID-19 patients using metformin and matched non-metformin, acarbose and matched non-acarbose 


$\begin{array}{cccc}\begin{array}{c}\text { Metformin } \\ (n=50)\end{array} & \begin{array}{c}\text { Matched non- } \\ \text { Metformin }\end{array} & \begin{array}{c}\text { Acarbose } \\ (n=46)\end{array} & \begin{array}{c}\text { Matched non- } \\ \text { acarbose } \\ \end{array} \\ (n=50) & & (n=46)\end{array}$

\begin{tabular}{|c|c|c|c|c|}
\hline \multicolumn{5}{|l|}{ Treatments } \\
\hline Antiviral therapy & 49(98.0) & $42(84.0) *$ & $41(89.1)$ & 43(93.5) \\
\hline Antibiotic therapy & $45(90.0)$ & $37(74.0) *$ & $40(87.0)$ & $40(87.0)$ \\
\hline systemic glucocorticoids & $17(34.0)$ & $16(32.0)$ & $12(26.1)$ & $22(47.8) \#$ \\
\hline Intravenous immunoglobulin & $15(30.0)$ & $11(22.0)$ & $11(23.9)$ & $22(47.8) \#$ \\
\hline Renal replacement therapy & $0(0.0)$ & $1(2.0)$ & $0(0.0)$ & $0(0.0)$ \\
\hline Insulin & $26(52.0)$ & $10(20.0)^{* *}$ & $23(50.0)$ & $39(84.8)^{\# \# \#}$ \\
\hline Metformin & 50 & 0 & $21(45.7)$ & $15(32.6)$ \\
\hline Sulfonylurea & $18(36.0)$ & $1(2.0) * * *$ & $17(37.0)$ & $8(17.4)^{\#}$ \\
\hline DPP-4 inhibitor & $3(6.0)$ & $0(0.0)$ & $3(6.5)$ & $3(6.5)$ \\
\hline Acarbose & $28(56.0)$ & $3(6.0) * * *$ & $46(100.0)$ & $0(0.0)$ \\
\hline thiazolidinedione & $6(12.0)$ & $0(0.0) *$ & $4(8.7)$ & $0(0.0)$ \\
\hline \multicolumn{5}{|l|}{ Oxygen support } \\
\hline Oxygenation & $32(64.0)$ & $21(42.0)$ & $30(65.2)$ & $30(65.2)$ \\
\hline Mechanical ventilation & $6(12.0)$ & $11(22.0)$ & $3(6.5)$ & $10(21.7)^{\#}$ \\
\hline \multicolumn{5}{|l|}{ Illness severity } \\
\hline Severe & $14(28.0)$ & $21(42.0)$ & $12(26.1)$ & $18(39.1)$ \\
\hline \multicolumn{5}{|l|}{ Complications } \\
\hline ARDS & $4(8.0)$ & $8(16.0)$ & $1(2.2)$ & $8(17.4)^{\#}$ \\
\hline $\mathrm{ACI}$ & $1(2.0)$ & $4(8.0)$ & $2(4.3)$ & $6(13.0)$ \\
\hline AKI & $0(0.0)$ & $0(0.0)$ & $0(0.0)$ & $2(4.3)$ \\
\hline Secondary infection & $8(16.0)$ & $5(10.0)$ & $0(0.0)$ & $2(4.3)$ \\
\hline Shock & $1(2.0)$ & $0(0.0)$ & $1(2.2)$ & $10(21.7)^{\#}$ \\
\hline Hypoproteinemia $<30 \mathrm{~g} / \mathrm{l}$ & $9(18.0)$ & $5(10.0)$ & $10(21.7)$ & $6(13.0)$ \\
\hline Coagulopathy & $6(12.0)$ & $9(18.0)$ & $8(17.4)$ & $10(21.7)$ \\
\hline Length of hospital stay, days & $17.60 \pm 8.74$ & $16.80 \pm 10.51$ & $18.37 \pm 8.15$ & $16.52 \pm 9.96$ \\
\hline ICU admission & $6(12.0)$ & $6(12.0)$ & $3(6.5)$ & $8(17.4)$ \\
\hline $\begin{array}{l}\text { Duration from admission to } \\
\text { ICU, d }\end{array}$ & $3.83 \pm 2.04$ & $2.83 \pm 2.14$ & $\begin{array}{l}6.00(3.50- \\
6.00)\end{array}$ & $2.50(2.00-5.00)$ \\
\hline \multicolumn{5}{|l|}{ prognosis } \\
\hline Discharged & $47(94)$ & $41(82)$ & $45(97.8)$ & $34(73.9)^{\# \#}$ \\
\hline Death & $3(6.0)$ & $9(18)$ & $1(2.2)$ & $12(26.1)$ \\
\hline
\end{tabular}

Data are expressed as $\mathrm{n}(\%)$, mean $\pm \mathrm{SD}$ or median (IQR). Comparison of metformin users and non-users: ${ }^{*} P<0.05,{ }^{* *} P<0.01,{ }^{* * *} P<0.001$. Comparison of acarbose users and non-users:: ${ }^{\#} P<0.05,{ }^{\# \#} P<0.01$, \#\#\# $P<0.05$. ARDS, acute respiratory distress syndrome; ACI, acute cardiac injury; AKI, acute kidney injury 
Table 8. Multivariate COX regression analysis on the risk factors associated with mortality of 1331 COVID-19 patients

\begin{tabular}{lcc}
\hline Factor & Hazard ratio & $\boldsymbol{P}$ value \\
\hline Sex (male) & $2.59(1.68-3.99)$ & $<0.001$ \\
Age & $1($ ref $)$ & \\
\hline $18-49$ & $5.86(2.27-15.12)$ & $<0.001$ \\
\hline $50-64$ & $11.8(4.6-30.2)$ & $<0.001$ \\
$\geq 65$ & $1.75(1.18-2.60)$ & 0.006 \\
\hline Hypertension & $4.55(2.52-8.20)$ & $<0.001$ \\
\hline CKD & & \\
& & \\
\hline CVD & & 0.006 \\
& $0.98(0.62-1.54)$ & 0.918 \\
\hline Diabetes & & \\
\hline
\end{tabular}

CKD, Chronic kidney disease; CVD, cerebrovascular disease.

Figures 


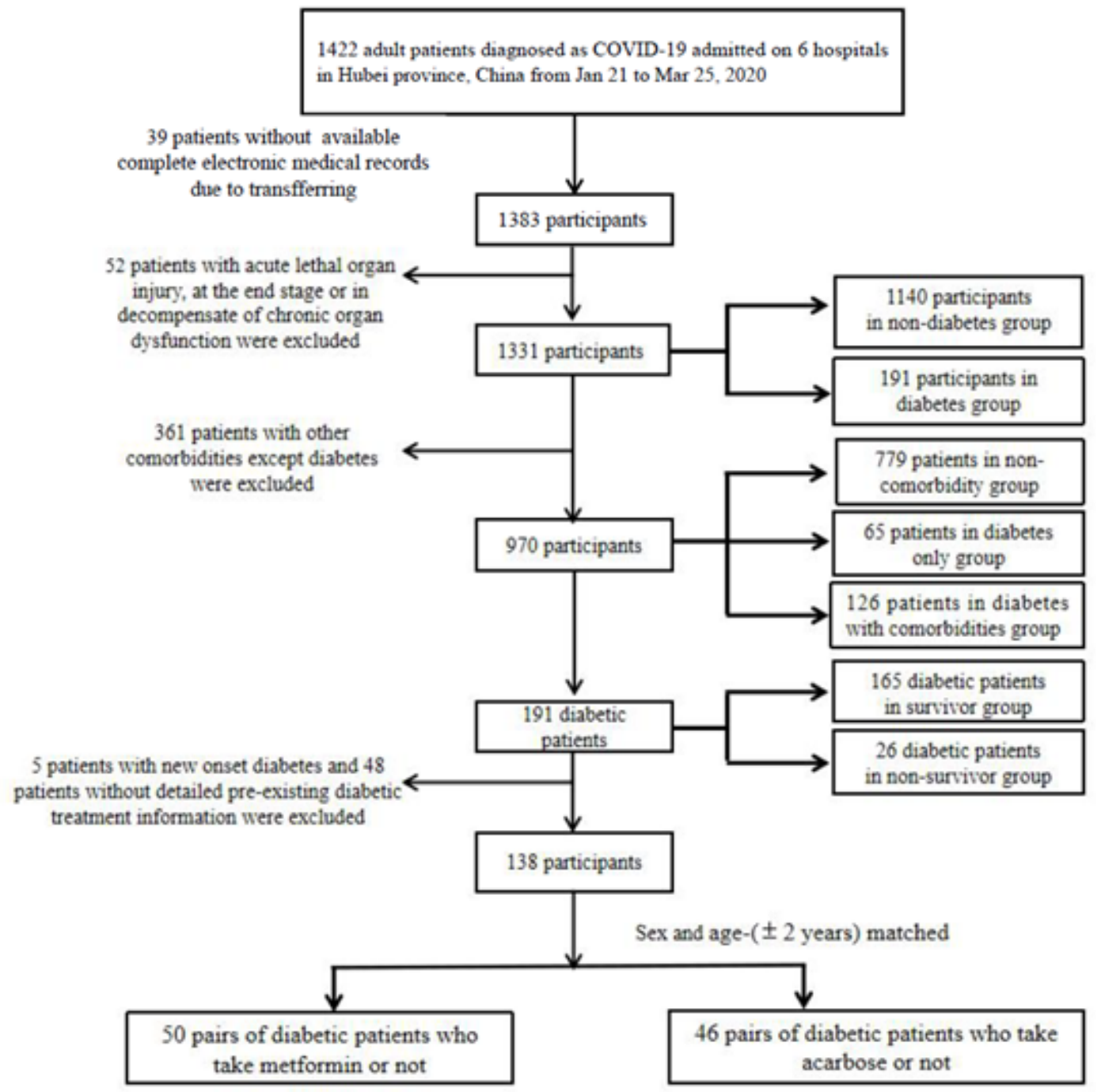

Figure 1

Flow chart of patient recruitment.

A

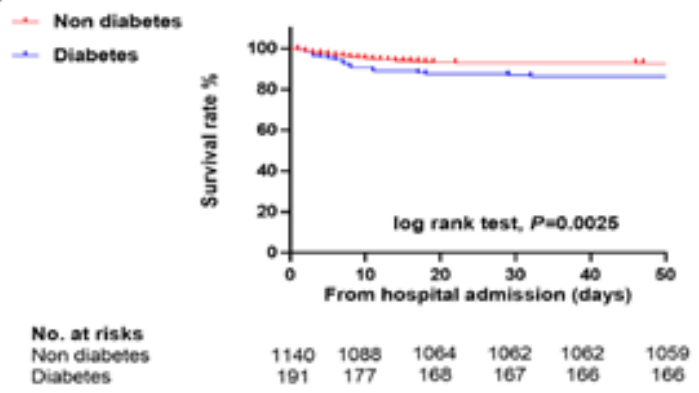

B

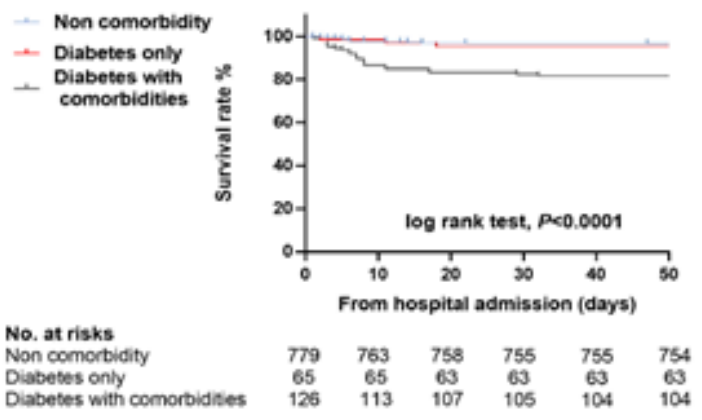

Figure 2

Kaplan-Meier survival curves of in-hospital mortality among patients with COVID-19. A, Kaplan-Meier survival curves for in-hospital mortality between diabetes and non-diabetes from hospital admission. B, Kaplan-Meier survival curves in-hospital mortality comparison of patients with non-comorbidity, diabetes 
only and diabetes with comorbidities from hospital admission. Compared patients with non-comorbidity and diabetes only from hospital admission ( Log rank test, $p=0.590$ ). Compared patients with onlydiabetes group and diabetes with comorbidities from hospital admission ( Log rank test, $p=0.009$ ).

\section{Supplementary Files}

This is a list of supplementary files associated with this preprint. Click to download.

- SupplementaryMaterials2.doc 